UNIVERSIDADE DE BRASÍLIA

FACULDADE DE TECNOLOGIA

DEPARTAMENTO DE ENGENHARIA FLORESTAL

PROGRAMA DE PÓS-GRADUAÇÃO EM CIÊNCIAS FLORESTAIS

MODELAGEM DE NICHO ECOLÓGICO PARA ESPÉCIES ARBÓREAS RARAS EM ÁREA SOB IMPACTOS ANTRÓPICOS NO SUDOESTE DA AMAZÔNIA

BRASILEIRA

TAMILIS ROCHA SILVA

ORIENTADOR: JOSÉ ROBERTO RODRIGUES PINTO COORIENTADOR: MARCELO BRILHANTE DE MEDEIROS DISSERTAÇÃO DE MESTRADO EM CIÊNCIAS FLORESTAIS

PUBLICAÇÃO: PPGEFL.DM-273/2016

BRASÍLIA/DF FEVEREIRO - 2016 


\section{MODELAGEM DE NICHO ECOLÓGICO PARA ESPÉCIES ARBÓREAS RARAS EM ÁREA SOB IMPACTOS ANTRÓPICOS NO SUDOESTE DA AMAZÔNIA BRASILEIRA}

\section{TAMILIS ROCHA SILVA}

Dissertação apresentada ao Departamento de Engenharia Florestal da Universidade de Brasília - UnB, como parte das exigências do curso de Pós-graduação em Ciências Florestais, para obtenção do título de Mestre.

Banca examinadora:

Prof. Dr. José Roberto Rodrigues Pinto

Universidade de Brasília - UnB

Departamento de Engenharia Florestal

(Orientador)

Prof. Dr. Ricardo de Oliveira Gaspar

Universidade de Brasília - UnB

Departamento de Engenharia Florestal

(Membro titular)

Dr. Alexandre Bonesso Sampaio

Instituto Chico Mendes de Conservação da Biodiversidade - ICMBio

(Membro titular)

Dr. Marcelo Fragomeni Simon

Pesquisador da Embrapa Recursos Genéticos e Biotecnologia - Embrapa Cenargen

(Membro suplente) 


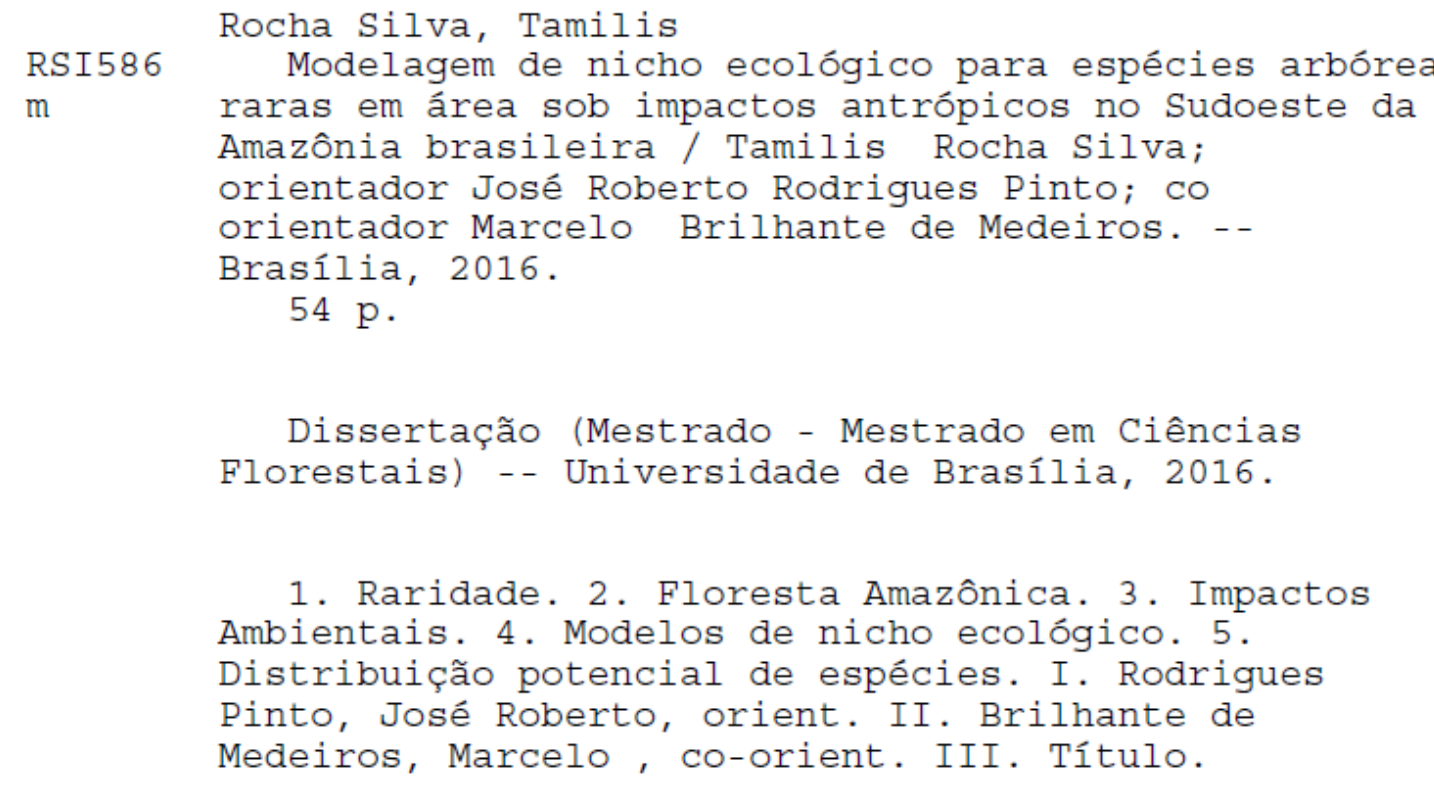

\section{CESSÃO DE DIREITOS}

AUTOR: Tamilis Rocha Silva

TÍTULO: Modelagem de nicho ecológico para espécies arbóreas raras em área sob impactos antrópicos no sudoeste da Amazônia brasileira

GRAU: Mestre ANO: 2016

É concedida à Universidade de Brasília (UnB) permissão para reproduzir cópias desta dissertação de mestrado e para emprestar ou vender tais cópias somente para propósitos acadêmicos e científicos. $\mathrm{O}$ autor reserva outros direitos de publicação e nenhuma parte dessa dissertação de mestrado pode ser reproduzida sem autorização por escrito do autor.

Tamilis Rocha Silva

tamilisrocha@hotmail.com 


\section{AGRADECIMENTOS}

Agradeço ao orientador Marcelo Brilhante pela confiança, paciência e por abrir as portas da Embrapa Cenargen e da Amazônia, o que tornou possível este crescimento profissional e pessoal fantástico. Imensamente grata, Marcelo!

Agradeço a orientação cuidadosa e paciente do professor José Roberto. Zé, obrigada por abraçar a causa!

Aos meus pais Edilamar, Mauricio e minhas irmãs Tais, Tássia por acreditarem e apoiarem, mesmo quando tudo parecia loucura... Brasília deu certo!

A Raissa, Pamela, Talita, Duda, Laura, Gabriela e colegas do Cenargen pelo apoio, amizade e auxílios de extrema importância para ter chegado até aqui! A atenção e carinho de vocês fizeram toda diferença no aprender!

Ao Serginho Noronha pela paciência em ensinar, pela amizade e por todo apoio dado a este trabalho.

Ao Bruno Walter, Marcelo Simon e demais pesquisadores do PBE do Cenargen pelo acolhimento, inúmeros ensinamentos, amizade e contribuições a este trabalho.

A minha equipe "master plus sensacional" de campo Antônio Barreto (grande mestre Tonico), Glocimar (querido Gloci), Valdeci (Dudu) e Fernanda Catenacci (minha amiga querida)! Muito obrigada pela paciência, pelo carinho e por tornarem a missão impossível ser possível, alegre e inesquecível!

A família brasiliense da 409 (Bel, Bi, Talita e Luma), amigos da 411- BotEco/Tapera e Neocolina! Com rock, samba e amor vocês tornaram o avião o melhor aconchego pra se viver!

A todo apoio e infraestrutura da Embrapa Cenargen e a Coordenação de Aperfeiçoamento de Pessoal de Nível Superior (CAPES) pela bolsa concedida. 


\section{SUMÁRIO}

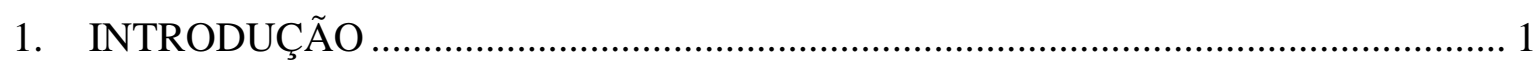

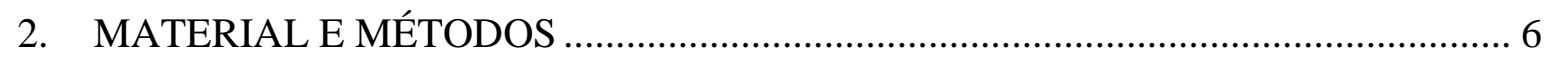

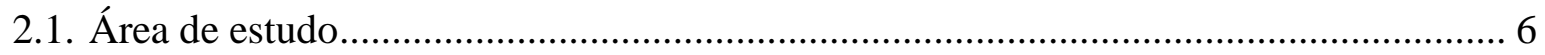

2.2. Coleta de dados ……………………………………......................................... 7

2.2.1. Escolha das espécies............................................................................................... 7

2.2.2. Pontos de presença e variáveis ambientais............................................................... 10

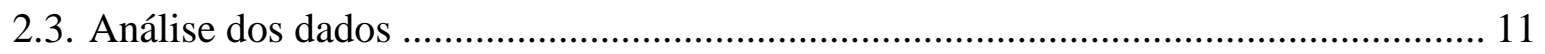

2.3.1. Modelagem do nicho potencial final .................................................................. 11

2.3.2. Determinação das áreas de impacto e porcentagens de perda de nicho ..................... 14

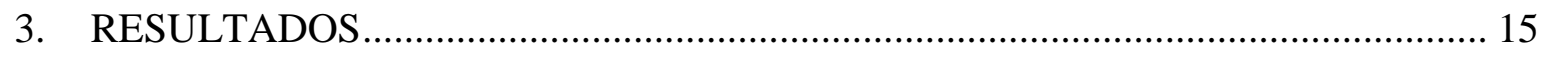

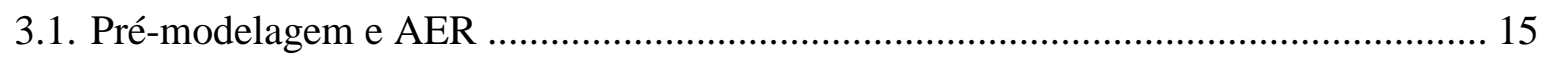

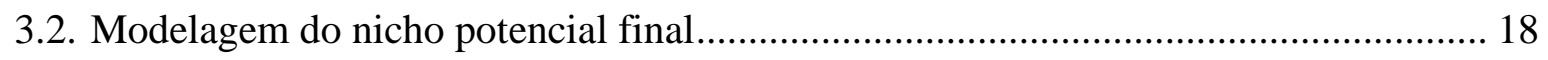

3.3. Determinação das áreas de impacto e porcentagens de perda de áreas de distribuição

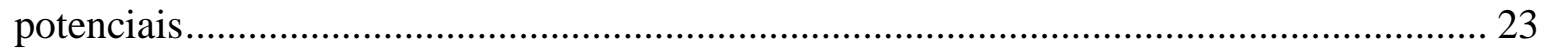

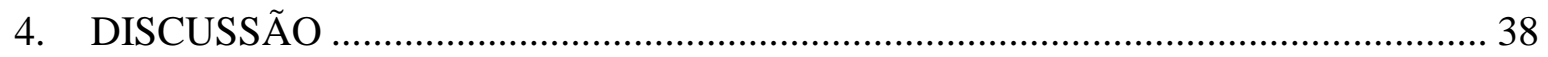

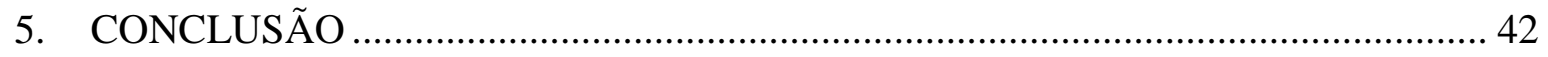

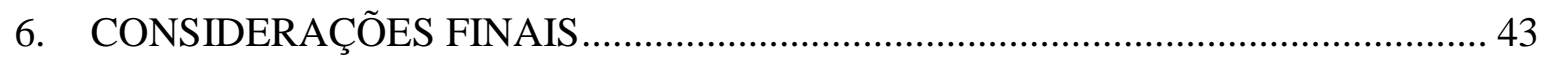

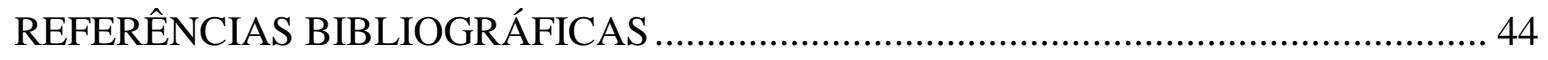




\section{LISTA DE TABELAS}

Tabela 1. Espécies localmente raras selecionadas para a modelagem de nicho ecológico potencial na bacia do alto rio Madeira, sudoeste da Amazônia brasileira. Número de indivíduos amostrados no inventário realizado de acordo com o protocolo RAPELD (Moser et al.2014). 9

Tabela 2. Número de indivíduos coletados a partir da pré-modelagem e caracterização dos ambientes de ocorrência das espécies localmente raras na bacia do alto rio Madeira, sudoeste da Amazônia brasileira, Brasil. .17

Tabela 3. Estatísticas de validação da modelagem de nicho potencial final. Valores de AUC (área sob a curva de características de funcionamento do receptor) e Kappa variam entre $0 \mathrm{e} 1$ 22

Tabela 4. Tamanho e porcentagem das áreas de distribuição potenciais de espécies arbóreas localmente raras na bacia do alto rio Madeira, sudoeste da Amazônia brasileira, Brasil e perda dos nichos por impactos "alagamento da UHE de Jirau" "desmatamento". 37 


\section{LISTA DE FIGURAS}

Figura 1. Localização da área de estudo na bacia do alto rio Madeira, sudoeste da Amazônia brasileira, Brasil. Em destaque a localização dos módulos de amostragem RAPELD para monitoramento da vegetação realizado pela Embrapa Cenargen, o local da barragem da UHE de Jirau e a rodovia BR 364.

Figura 2. Exemplo do mapa gerado pela pré-modelagem do nicho potencial de Nealchornea yapurensis Huber na área de influência direta e indireta da UHE de Jirau, na bacia do alto rio Madeira, sudoeste da Amazônia brasileira, Brasil. A distribuição potencial da espécie está representada em vermelho (Imagem Landsat8 de agosto de 2014, UTM zona 20S, DATUM: WGS 84).

Figura 3. Conteúdo de argila $(\mathrm{g} / \mathrm{Kg})$ na bacia do alto rio Madeira, sudoeste da Amazônia brasileira, Brasil.

Figura 4. Conteúdo de areia $(\mathrm{g} / \mathrm{Kg})$ na bacia do alto rio Madeira, sudoeste da Amazônia brasileira, Brasil.

Figura 5. Conteúdo de silte $(\mathrm{g} / \mathrm{Kg})$ na bacia do alto rio Madeira, sudoeste da Amazônia brasileira, Brasil.

Figura 6. Conteúdo de soma de bases $(\mathrm{cmolc} / \mathrm{kg}$ ) na bacia do alto rio Madeira, sudoeste da Amazônia brasileira, Brasil.

Figura 7. Área de distribuição potencial de Annona neoinsignis H, Rainer e os impactos 'alagamento da UHE de Jirau' e 'desmatamento' na bacia do alto rio Madeira, sudoeste da Amazônia brasileira, Brasil (Imagem de agosto de 2014, UTM zona 20S, DATUM: WGS 84). .23

Figura 8. Área de distribuição potencial de Brosimum parinarioides Ducke e os impactos 'alagamento da UHE de Jirau' e 'desmatamento' na bacia do alto rio Madeira, sudoeste da Amazônia brasileira, Brasil (Imagem de agosto de 2014, UTM zona 20S, DATUM: WGS 84).

Figura 9. Área de distribuição potencial de Chaunochiton kappleri (Sagot ex Engl,) Ducke e os impactos 'alagamento da UHE de Jirau' e 'desmatamento' na bacia do alto rio Madeira, sudoeste da Amazônia brasileira, Brasil (Imagem de agosto de 2014, UTM zona 20S, DATUM: WGS 84).

Figura 10. Área de distribuição potencial de Chrysophyllum colombianum (Aubrév.) T.D.Penn, e os impactos 'alagamento da UHE de Jirau' e 'desmatamento' na bacia do alto rio Madeira, sudoeste da Amazônia brasileira, Brasil (Imagem de agosto de 2014, UTM zona 20S, DATUM: WGS 84). 
Figura 11. Área de distribuição potencial de Buchenavia congesta Ducke e os impactos 'alagamento da UHE de Jirau' e 'desmatamento' na bacia do alto rio Madeira, sudoeste da Amazônia brasileira, Brasil (Imagem de agosto de 2014, UTM zona 20S, DATUM: WGS 84).

Figura 12. Área de distribuição potencial de Lacunaria jenmanni (Oliv,) Ducke e os impactos 'alagamento da UHE de Jirau' e 'desmatamento' na bacia do alto rio Madeira, sudoeste da Amazônia brasileira, Brasil (Imagem de agosto de 2014, UTM zona 20S, DATUM: WGS 84).

Figura 13. Área de distribuição potencial de Moronobea coccinea Aubl, e os impactos 'alagamento da UHE de Jirau' e 'desmatamento' na bacia do alto rio Madeira, sudoeste da Amazônia brasileira, Brasil (Imagem de agosto de 2014, UTM zona 20S, DATUM: WGS 84).

Figura 14. Área de distribuição potencial de Nealchornea yapurensis Huber e os impactos 'alagamento da UHE de Jirau' e 'desmatamento' na bacia do alto rio Madeira, sudoeste da Amazônia brasileira, Brasil (Imagem de agosto de 2014, UTM zona 20S, DATUM: WGS 84). 30

Figura 15. Área de distribuição potencial de Qualea tessmannii Mildbr, e os impactos 'alagamento da UHE de Jirau' e 'desmatamento' na bacia do alto rio Madeira, sudoeste da Amazônia brasileira, Brasil (Imagem de agosto de 2014, UTM zona 20S, DATUM: WGS 84).

Figura 16. Área de distribuição potencial de Rauvolfia sprucei Müll,Arg, e os impactos 'alagamento da UHE de Jirau' e 'desmatamento' na bacia do alto rio Madeira, sudoeste da Amazônia brasileira, Brasil (Imagem de agosto de 2014, UTM zona 20S, DATUM: WGS 84).

Figura 17. Área de distribuição potencial de Semaphyllanthe megistocaula (K.Krause) L.Andersson e os impactos 'alagamento da UHE de Jirau' e 'desmatamento' na bacia do alto rio Madeira, sudoeste da Amazônia brasileira, Brasil (Imagem de agosto de 2014, UTM zona 20S, DATUM: WGS 84)......

Figura 18. Área de distribuição potencial de Vochysia biloba Ducke e os impactos 'alagamento da UHE de Jirau' e 'desmatamento' na bacia do alto rio Madeira, sudoeste da Amazônia brasileira, Brasil (Imagem de agosto de 2014, UTM zona 20S, DATUM: WGS $84)$.

Figura 19. Área de distribuição potencial de Xylopia benthamii R.E.Fr e os impactos 'alagamento da UHE de Jirau' e 'desmatamento' na bacia do alto rio Madeira, sudoeste da Amazônia brasileira, Brasil (Imagem de agosto de 2014, UTM zona 20S, DATUM: WGS 84). 
Figura 20. Áreas de distribuição potencial perdidas em porcentagem por impactos "alagamento da UHE de Jirau" e "desmatamento" para 13 espécies arbóreas localmente raras na bacia do alto rio Madeira, sudoeste da Amazônia brasileira, Brasil. ...................... 36 


\section{RESUMO}

Espécies raras são importantes no equilíbrio e funcionamento dos ecossistemas e na conservação da biodiversidade. No entanto, populações raras possuem características específicas que as tornam mais vulneráveis diante de distúrbios antrópicos. Este trabalho teve como objetivo avaliar os impactos de modificações da paisagem natural sobre as áreas de distribuição potencial de 13 espécies arbóreas localmente raras no sudoeste da Amazônia brasileira. Foram utilizados modelos de nicho ecológico para mapear a distribuição potencial destas espécies. A partir das classificações de imagens de satélite foram identificados dois principais impactos na área de estudo: o 'alagamento causado pela usina hidrelétrica de Jirau' e o 'desmatamento' gerado pela construção da usina hidrelétrica de Jirau, agropecuária, urbanização e estradas. As porcentagens de perdas de áreas de distribuição potencial para cada espécie foram calculadas por interseção de imagens dos impactos sobre as áreas potenciais geradas pela modelagem de nicho ecológico. $\mathrm{O}$ 'desmatamento' causou perdas de áreas de distribuição potencial das espécies arbóreas raras entre 6,7\% e 34,1\%. As espécies mais atingidas por este impacto foram Moronobea coccinea Aubl. (34,1\%), Vochysia biloba Ducke $(15,7 \%)$ e Xylopia benthamii R.E.Fr. (15,4\%). O impacto pelo 'alagamento da UHE de Jirau' variou entre 1,7\% e 8,2\% em perdas de áreas de distribuição das espécies raras deste trabalho. A espécie mais atingida por este impacto foi Buchenavia congesta Ducke $(4,3 \%)$. As espécies com maior vulnerabilidade na área com a soma dos dois impactos foram Moronobea coccine e Vochysia biloba. Os resultados indicam o sinergismo de impactos antrópicos na região e a considerável magnitude destes distúrbios para as espécies raras, com perdas significativas de áreas potenciais às populações mais vulneráveis ao antropismo. As informações geradas a partir das espécies raras se mostraram de grande importância para a avaliação de impactos antrópicos, estratégias de manutenção e conservação de ecossistemas vulneráveis.

Palavras chaves: Raridade, Floresta Amazônica, impactos ambientais, modelos de nicho ecológico, distribuição potencial de espécies. 


\begin{abstract}
Rare species are important in balance and functioning of ecosystems and biodiversity conservation. However, rare populations have specific characteristics that make them more vulnerable to anthropic disturbances. This work aimed evaluate the impacts of changes in the natural landscape of the potential distribution areas of 13 locally rare tree species in the southwest of the Brazilian Amazon. Ecological niche models were used to map the potential distribution of these species. From the satellite images classifications were identified two main impacts in the study area: the 'flooding caused by the the Jirau hydroelectric dam' and 'deforestation' generated by the construction of the Jirau hydroelectric dam, agriculture, urbanization and roads. The percentages of potential distribution areas of loss for each species were calculated by intersection of images of the impact on potential areas generated by ecological niche modeling. The 'deforestation' caused losses of potential distribution areas of rare tree species between $6.7 \%$ and $34.1 \%$. The species most affected by the impact were Moronobea coccinea Aubl. (34.1\%), Vochysia biloba Ducke (15.7\%) and Xylopia benthamii R.E.Fr. (15.4\%). The impact of the 'flooding of the UHE Jirau' varies between $1.7 \%$ and $8.2 \%$ losses of distribution areas of rare species of this work. The species most affected by this impact was Buchenavia congested Ducke (4.3\%). The species with the most vulnerable in the area with the sum of the two impacts were Moronobea coccine and Vochysia biloba. The results indicate synergism of human impacts in the region and the considerable magnitude of these disturbances to rare species, with significant loss of potential areas to the most vulnerable populations to anthropism. The information generated from the rare species was of great importance for the evaluation of human impacts, maintenance and conservation strategies of vulnerable ecosystems.
\end{abstract}

Key words: Rarity, Amazon Forest, environmental impacts, ecological niche models, potential distribution of species. 


\section{APRESENTAÇÃO}

A mega diversidade registrada na Amazônia representa grande parte da riqueza de espécies do planeta, o que atribui a este bioma desafios em estudos naturais (Ter Steege et al. 2003; Forley et al. 2007; Hubbell et al. 2008; Higgins et al. 2011). A composição arbórea da Floresta Amazônica se faz em grande percentual por espécies raras, muitas delas sem registros em herbários ou ainda pouco conhecidas (Pitman et al. 1999; Pitman et al. 2001; ter Steege et al. 2013). Espécies raras são consideradas aquelas com populações pouco abundantes, com distribuição geográfica restrita, habitats específicos, baixa capacidade competitiva e dispersão limitada (Rabinowitz 1981; Kunin \& Gaston 1997; Markham 2014).

As interações de espécies raras com o ecossistema em que estas estão inseridas têm importância na estrutura e função de comunidades e na conservação da biodiversidade (Schemske et al. 1994; Saetersdal 1994; Rodrigues \& Gaston 2002; Flather \& Sieg 2007; Booth et al. 2011; Gaston 2012). Entretanto, as características específicas da raridade de espécies quanto à abundância, à distribuição geográfica, às variações morfológicas e à variabilidade genética as tornam mais vulneráveis diante de impactos ambientais (Gaston 1998; Henle et al. 2003; Davies et al. 2004; Gaston 2012). Assim, a carência em estudos voltados às populações raras, principalmente na vasta diversidade da Amazônia, alerta para a possibilidade de perda de informações biológicas diante de impactos antrópicos (Ricklefs 2000; Hubbell 2013; ter Steege et al. 2013). Esta ausência de informação coloca em risco a manutenção e conservação das espécies raras diante da ocupação antrópica.

A Amazônia brasileira, desde a década de 1970, sofre impactos ambientais com a expansão urbana, agrícola, pecuária, exploração madeireira e construção de grandes hidrelétricas (Laurance et al. 2002; Benítez-Malvido et al. 2003; Ferraz et al. 2005; Fearnside 2005; Laurance et al. 2009; Laurance et al. 2011; Finer \& Jenkins 2012; Ferreira et al. 2014). Esta contínua transformação das paisagens amazônicas pela exploração dos recursos naturais e desmatamento representa grande risco para a perda de biodiversidade, e pode incluir a extinção de muitas espécies, principalmente as raras (Ricklefs 2000; Hubbell et al. 2008; te Steege et al. 2015).

Os estudos com populações raras podem gerar informações importantes sobre áreas vulneráveis que necessitam de maior atenção em programas de conservação da natureza (Guisan et al. 2005; Giulietti et al. 2009; Martinelli et al. 2014). Neste contexto, os modelos 
de nicho ecológico são ferramentas computacionais que apresentam resultados úteis e viáveis para estudos de raridade de espécies em áreas pouco conhecidas ou de difícil acesso (Raxworthy et al. 2003; Engler et al. 2004; Pearson et al. 2007; Guisan et al. 2006; Giovanelli et al. 2008; Siqueira et al. 2008), como é o caso da região Amazônica. A modelagem correlaciona dados de ocorrência das espécies e informações ambientais com o conceito de nicho fundamental de Hutchinson (Hutchinson 1957), representado pela distribuição potencial (Soberón \& Peterson 2005). A partir de mapas da distribuição potencial das espécies alvo é possível gerar informações para medidas de mitigação ou conservação de áreas com ocorrência destas populações (Guarino et al. 2012; Marcer et al. 2013).

Este trabalho está organizado em um único capítulo. Nele foram utilizados modelos de nicho ecológico para avaliar os impactos ambientais sobre as áreas de distribuição potencial de espécies arbóreas localmente raras na bacia do alto rio Madeira, sudoeste da Amazônia brasileira. Nesta região foram construídas duas grandes hidrelétricas na última década, Jirau e Santo Antônio. Este estudo está inserido no programa de pesquisa para o monitoramento dos impactos da hidrelétrica de Jirau sobre a vegetação da área de influência deste empreendimento. Estudos prévios sobre a composição e a estrutura da vegetação arbórea e herbácea na região foram realizados (Moser et al. 2014) com o método RAPELD (Magnusson et al. 2005). Além destas duas hidrelétricas, a região tem sido alvo de intensa transformação da paisagem por outras atividades antrópicas nas últimas três décadas, como construção de estradas e implantação de atividades voltadas ao agronegócio (Ferraz et al. 2005). 


\section{INTRODUÇÃO}

A raridade é fenômeno característico atribuído a algumas espécies e pode ser causada por vários fatores específicos (Rabinowitz 1981; Gaston 1994). Alguns trabalhos investigaram as causas deste fenômeno para sistematizar e compreender melhor os fatores que determinam a espécie como rara (Preston 1948; Preston 1962; Rabinowitz et al. 1986; Fiedler 1987; Kunin 1998; Kunin \& Gaston 1997; Gaston 1994; Candotte 2002). Entre os indicadores e classificadores da raridade, a abundância e a distribuição geográfica são as principais variáveis a serem consideradas (Brown 1984). Espécies raras são pouco abundantes e geralmente possuem distribuição geográfica restrita (Gaston 1994).

Em geral as espécies raras ocupam nichos incomuns por terem exigências do habitat estreitas (especialistas), baixa capacidade competitiva e dependência na habilidade e capacidade de dispersão (Markham 2014). A dinâmica populacional de espécies raras pode seguir padrões peculiares com restrições morfológicas, reprodutivas, genéticas, sucessionais e ambientais que devem ser observadas com atenção (Kunin \& Gaston 1993). Essas limitações podem comprometer a permanência da espécie na área ou até mesmo o funcionamento do ecossistema (Gaston 1994; Lavergne et al. 2006).

Populações raras e suas interações são importantes na riqueza, estrutura e dinâmica de comunidades, influenciando na conservação da biodiversidade (Schemske et al. 1994; Saetersdal 1994; Rodrigues \& Gaston 2002; Flather \& Sieg 2007; Booth et al. 2011). Estudos comparativos entre espécies raras e comuns mostram que grande parte dos táxons em comunidades é incomum ou raro, tornando este último grupo proporcionalmente tão contribuinte nos padrões de diversidade quanto o de espécies comuns (Lennon et al. 2004; Cunningham \& Lindenmayer 2005). Mouillot et al. (2013) consideram que a perda de algumas interações entre espécies raras e comuns pode causar maior vulnerabilidade à diversidade ecológica, o que pode gerar alterações estruturais e funcionais nos ambientes. Durante muito tempo estudos sobre interações e processos ecológicos foram baseados somente em espécies comuns, o que torna necessário maiores pesquisas sobre a aplicação destas teorias para as espécies raras (Williams 2000; Cofre et al. 2007). 
A perda de espécies menos comuns ou raras pode alterar de forma significativa o funcionamento dos ecossistemas (Lyons et al. 2001; Lyons et al. 2005). Trabalhos sobre diversidade funcional relacionados à estrutura biótica discutem a existência de espécies raras redundantes e aquelas consideradas singulares, que carregam traços funcionais únicos que afetam desde a retenção e ciclagem de nutrientes até a resistência a espécies invasoras no ambiente (Naeem \& Wright 2003; Lyons et al. 2001; Flather \& Sieg 2007). Estas populações raras contem características singulares que muitas vezes destacam-se como 'espécies-chaves' ou 'bioindicadoras', em que suas distribuições, abundâncias ou interações podem inferir informações sobre o ambiente e sobre outros grupos (Marcot \& Flather 2007; Mcgeoch 2013; Martinelli et al. 2014). Lyons et al. (2005) discutem situações em que a perda de determinada espécie rara gerou o declínio de serviços ecossistêmicos, com o aumento excessivo ou o desaparecimento de determinadas populações e/ou recursos, o que resultou em desequilíbrio ambiental.

A escala é outro fator imprescindível para determinar o tipo da raridade e para diferenciar populações raras de comuns (Rabinowitz 1981; Schoener 1987; Wamelink et al. 2014). As avaliações da raridade e do estado de conservação de espécies em escalas local, regional e global podem apresentar diferenças significativas nos resultados (Hartley \& Kunin 2003; Broennimann et al. 2005). Alguns estudos apontam que determinados grupos de espécies possuem associação positiva entre o alcance geográfico e a abundância, em que estas populações podem ser consideradas raras localmente, porém não regionalmente (Hanski 1982; Yu \& Dobson 2000). Outros trabalhos reforçam que esta relação de raridade local varia entre as biotas de acordo com a escala e com os limites geográficos (Brown 1984; Schoener 1987; Harrison et al. 2008). He \& Condit (2007) ressaltam que para estudo de raridade o refinamento da escala (escala local) é de grande importância para obter resultados mais precisos por reduzir dados tendenciosos e fornecer melhores informações biológicas.

A raridade local é considerada padrão frequente entre espécies arbóreas da Amazônia (Pitman et al. 1999; Pitman et al. 2001; Ricklefs 2000). As comunidades arbóreas da bacia Amazônica são compostas pela hiperdominância de algumas espécies e pelo grande número de espécies raras para as quais a distribuição geográfica ainda é algo incerto de se determinar (ter Steege et al. 2013; Hubbell 2013). Segundo ter Steege (2013) muitas destas espécies raras que compõe a biodiversidade Amazônica nunca tiveram amostras férteis coletadas devido à grande dificuldade de encontrar indivíduos em estado 
fértil e por isso não foram adequadamente identificadas, o que se configura num problema para a conservação.

A diversidade de ambientes das Florestas Tropicais é uma das explicações apontadas para explicar o grande número de espécies raras que compõem estas formações, em que a especialização das espécies é dada pelo filtro ambiental (Pitman et al. 1999; Chuyong et al. 2011). Outra teoria que se aplica a raridade arbórea local da Amazônia é a do modelo nulo de Hubbell (Hubell 2001). Esta teoria defende que grande parte destas espécies raras que possuem a característica de serem generalistas e com distribuição muito ampla no bioma, se dispersam de forma estocástica e limitada com especiação randomizada (Hubell 2001; Hubbell 2013).

No clássico livro “A origem das espécies” Darwin (1859) afirma que a raridade é um dos precursores da extinção. Espécies raras não necessariamente são iminentes no risco de extinção, entretanto espécies consideradas ameaçadas são quase sempre raras (Gaston 2012). O processo de exclusão e extinção dos nichos de espécies localmente raras pode ser acelerado por impactos ambientais devido às limitações em tamanho populacional, restrições reprodutivas e distribuição geralmente restrita destas espécies (Gaston 1998; Henle et al. 2003; Davies et al. 2004). A condução da extinção de uma espécie pode variar com o tipo de raridade ou com o evento impactante (Harnik et al. 2012). Alguns trabalhos reforçam que as consequências das ações humanas sobre a perda de habitat de espécies e consequentes extinções pode gerar raridade conduzida, em que mesmo espécies não consideradas raras biologicamente, passam a ser raras ou extintas localmente (Davies et al. 2004; Courchamp et al. 2006; Lindenmayer et al. 2011; Fattorini 2014).

Estudos de monitoramento de populações raras têm importância em programas de conservação da natureza devido à contribuição na identificação de áreas que necessitam de maior atenção (Guisan et al. 2005; Giulietti et al. 2009; Martinelli et al. 2014). Neste contexto, a Floresta Amazônica vem passando por acelerados processos de fragmentação devido à exploração desordenada dos recursos naturais, o que tem alertado pesquisadores sobre a perda de biodiversidade e sobre o risco de extinção de espécies (Benítez-Malvido et al. 2003; Ferraz et al. 2005; Fearnside 2005; Broadbent et al. 2008; Hubbell et al. 2008; Laurance et al. 2011; Ferreira et al. 2014). A agropecuária, a exploração madeireira, a construção de estradas, linhas de energia, gasodutos e hidrelétricas estão entre as principais atividades humanas modificadoras da paisagem natural da Amazônia, o que tem gerado 
distúrbios com efeitos mais extremos do que possivelmente ocorreria em outros ecossistemas (Laurance et al. 2002; Laurance et al. 2009).

A proliferação da construção de hidrelétricas na bacia Amazônica nos últimos anos tem gerado polêmicas quanto aos impactos ambientais causados e aos reflexos na conservação da natureza (Ferreira et al. 2013). As extensas inundações e as grandes áreas desmatadas na construção das usinas, barramentos e estradas agem em proporções negativas de forma direta e intensa na dinâmica das comunidades e populações (Soito \& Freitas 2011; Finer \& Jenkins 2012; Jansson et al. 2000). A interrupção da conectividade entre rios, corredores ecológicos e fragmentos causados por estes empreendimentos pode afetar as condições mínimas de migração, dispersão e polinização das espécies, o que para populações raras pode ser crítico (Poff et al. 1997; Andersson et al. 2000; McAllister et al. 2001; Merrit et al. 2010).

O uso de tecnologias computacionais tem contribuído no processo de obtenção de dados da ocorrência potencial de espécies de forma viável e eficaz, em áreas de difícil acesso, com grandes obstáculos, como áreas sob influência de hidrelétricas (Guarino et al. 2012). Entre as ferramentas tecnológicas, os modelos de nicho ecológico se consolidaram atualmente como uma das principais técnicas auxiliares em estudos de conservação da natureza (Elith et al. 2006). Este tipo de modelagem quantifica as relações espéciesambiente baseadas em hipóteses de como fatores ambientais controlam a distribuição de espécies e comunidades (Peterson 2001).

A relação entre espécies e fatores ambientais é representada no preditivo geográfico definido como distribuição potencial e está correlacionada à teoria do nicho ecológico de Hutchinson (Soberón \& Peterson 2005). O nicho ecológico é diferenciado em fundamental ou potencial, que corresponde às dimensões do espaço ambiental que permitem que as populações existam indefinidamente; e em nicho realizado, que é a porção do nicho fundamental se considerado as interações interespecíficas (Hutchinson 1957; Peterson et al. 2011; Giannini et al. 2012). Assim, os modelos utilizam algoritmos que combinam dados de ocorrências populacionais com as possíveis variáveis bióticas e abióticas que podem influenciar o nicho fundamental das populações e geram mapas com áreas de presenças e ausências potenciais (Anderson et al. 2003; Guisan \& Zimmermann 2000).

A escolha dos descritores ambientais a serem utilizados na modelagem de nicho ecológico é importante parâmetro a ser considerado (Huston, 2002; Araújo \& Guisan 2006; 
Dormann 2007). As variáveis do ambiente utilizadas devem considerar as particularidades das possíveis interações da espécie com o ecossistema inserido e a escala espacial, não havendo conhecimento limitado no uso destas para gerar modelos confiáveis (Graf et al. 2005; Guisan \& Thuiller 2005; Ficetola et al. 2014). Dentre os descritores ambientais abióticos, dados climáticos e de solo estão entre os mais usados para escalas maiores, enquanto que para meso-escalas e locais o refinamento com dados topográficos e de cobertura da terra são apontados como mais adequados (Pearson e Dawson 2003; Araújo et al. 2005; Guisan e Thuiller 2005; Scull et al. 2005; Phillips et al. 2006; Austin \& Niel 2010).

Os modelos de nicho ecológico são apontados como grandes facilitadores na predição e ou detecção das áreas de ocorrência potenciais de espécies raras ou pouco estudadas (Raxworthy et al. 2003; Engler et al. 2004; Guisan et al., 2005; Pearson et al. 2007; Giovanelli et al. 2008; Siqueira et al. 2008; Marcer et al. 2013). Mesmo com os desafios quanto à natureza dos dados em estudos de espécies raras, alguns algoritmos consideram os poucos registros de ocorrências, juntamente com critérios adequados na escolha dos descritores ambientais, o que gera predições satisfatórias (Pearson et al. 2007; De Marco Jr \& Siqueira 2009).

Diante da vasta dimensão de diversidade biológica registrada na Floresta Amazônica, os modelos de nicho ecológico podem ser ferramentas úteis em estudos com táxons raros ou pouco conhecidos (Hopkins 2007). Considerando a vulnerabilidade das espécies raras às ações antrópicas em regiões com elevada biodiversidade, este estudo procurou responder a seguinte questão: qual o impacto de distúrbios antrópicos, como hidrelétricas e desmatamentos por uso e ocupação da terra, sobre a área de distribuição potencial de espécies arbóreas raras na Amazônia? Este trabalho teve como objetivo avaliar os impactos de modificações da paisagem natural sobre as áreas de distribuição potencial de espécies raras. Para tanto, foram utilizados modelos de nicho ecológico para mapear a distribuição potencial de 13 populações arbóreas localmente raras no sudoeste da Amazônia brasileira, a fim de avaliar os impactos antrópicos sobre as áreas de ocorrências destas espécies. 


\section{MATERIAL E MÉTODOS}

\section{1. Área de estudo}

O estudo foi realizado em trechos da bacia do alto rio Madeira, localizados no município de Porto Velho, noroeste do estado de Rondônia, sob a influência do reservatório da Usina Hidrelétrica de Jirau e da linha de transmissão do empreendimento (Figura 1). Esta área de $9.422,92 \mathrm{~km}^{2}$ inclui a região onde estão sendo realizados estudos de inventário florístico e de monitoramento da vegetação pela Embrapa Recursos Genéticos e Biotecnologia - Cenargen desde 2011 (Moser et al. 2014; Perigolo 2014).

A região possui clima do tipo Tropical Úmido Hipertérmico (Cochrane e Cochrane 2010), com temperaturas anuais que variam entre $20^{\circ}$ e $35^{\circ} \mathrm{C}$ e umidade relativa média do ar entre 85 e 90\% (INMET). O regime pluviométrico médio anual oscila entre 2.000 e $2.200 \mathrm{~mm}$ (Sombroek 2001).

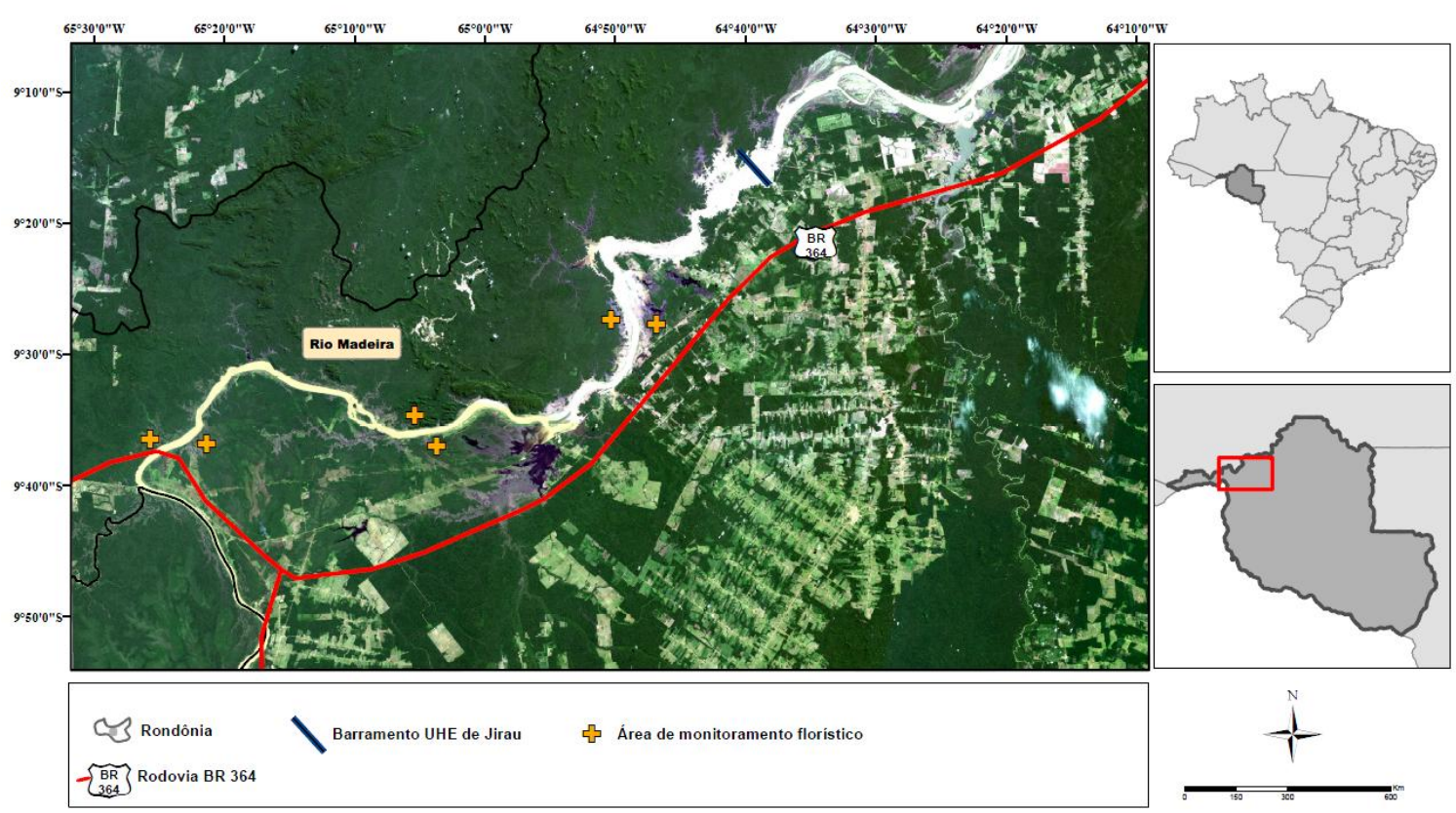

Figura 1. Localização da área de estudo na bacia do alto rio Madeira, sudoeste da Amazônia brasileira, Brasil. Em destaque a localização dos módulos de amostragem RAPELD para monitoramento da vegetação realizado pela Embrapa Cenargen, o local da barragem da UHE de Jirau e a rodovia BR 364.

A vegetação da região é heterogênea, com transições de fitofisionomias predominantes por Floresta Ombrófila Aberta (Floresta de Terra Firme), Floresta Ombrófila Densa, Densa Aluvial (Floresta de Várzea) e Campinaranas (IBGE 2012; Perigolo 2014). Os solos são 
compostos em sua maioria por Latossolos Vermelho - Amarelo Distróficos nas formações de Floresta Ombrófila Aberta; Gleissolos Háplicos Distróficos e Neossolos Flúvicos ou solos aluviais nas Campinaranas arbóreas e transição com Campinaranas Florestadas nas margens do rio Madeira (Cochrane e Cochrane 2010). O relevo da região é predominantemente plano, com altitudes que variam entre os $100 \mathrm{~m}$, entretanto algumas áreas apresentam elevações que podem chegar aos $300 \mathrm{~m}$ (Perigolo 2014).

As duas margens do rio Madeira na área de estudo diferem-se significativamente em relação à paisagem e ao estado de conservação da vegetação. A margem esquerda, localizada entre as divisas dos estados de Rondônia, Amazonas e Acre, é caracterizada por ser mais preservada e engloba o Parque Nacional Mapinguari, que mantém formações de Florestas Ombrófila Aberta e Densa em uma área de 1.776.914,18 hectares (BRASIL 2008; BRASIL 2012). Este lado do rio possui maiores variações em altitude e topografia que refletem formações geológicas com rochas de origem intrusiva e vulcânica (rochas metamórficas e ígneas) (Rizzotto et al. 2004; Cochrane \& Cochrane 2010).

A margem direita do rio tem origem em formações geológicas mais recentes por Depósitos Aluvionares e Coberturas Sedimentares (rochas sedimentares e rochas não consolidadas), contém planícies de Gleissolos mal drenadas e Latossolos bem drenadas (Cochrane \& Cochrane 2010). É caracterizada por Florestas Ombrófila Aberta com transições com as várzeas e Campinaranas, porém a paisagem deste lado do rio é altamente antropizada e consequentemente fragmentada por grandes fazendas e inúmeros acessos a rodovia BR-364 (Moser 2013; Perigolo 2014).

\subsection{Coleta de dados}

\subsubsection{Escolha das espécies}

A escolha das espécies foi feita a partir do banco de dados dos estudos de composição e estrutura da vegetação arbórea, desenvolvidos pela Embrapa Cenargen entre os anos de 2011 e 2014 (Moser et al. 2014; Perigolo 2014). Estes estudos foram realizados por meio do método RAPELD, o qual consiste numa combinação de protocolos do Rapid Assessment Protocol (RAP) com o método das Pesquisas Ecológicas de Longa Duração (LTER) (Magnusson et al. 2005). As parcelas utilizadas pela Embrapa foram alocadas de forma sistemática em transeções perpendiculares ao rio Madeira em sistema modular. Cada 
módulo é formado por duas transeções de $5 \mathrm{~km}$ de comprimento, separados por $1 \mathrm{~km}$. A alocação das parcelas considerou apenas a formação Floresta Ombrófila Aberta (incluindo Florestas de Terra Firme e a Floresta de Várzea), e incluiu algumas transições entre esta fitofisionomia e Campinaranas.

Nesses estudos realizados pela Embrapa Cenargen foram amostrados 8.504 indivíduos arbóreos e 909 espécies, sendo que grande parte destas foram consideradas raras por apresentarem baixa abundância (Moser et al. 2014). Entre estas espécies raras, 13 foram escolhidas para este trabalho, as quais apresentaram identificação e nomenclatura taxonômicas consistentes, com material botânico armazenado e revisado no Herbário da Embrapa Cenargen - Herbário Cen (Tabela1).

Os critérios para escolha dessas espécies seguem dentro da classificação de raridade local, segundo Rabinowitz (1981). Considerou-se a abundância máxima de três indivíduos em todo o inventário (26 ha), mantendo a proporção de $<1$ indivíduo/ha e a distribuição geográfica restrita ao bioma Amazônico, conferida na rede speciesLink (disponível em: http://www.splink.org.br), na Lista de Espécies da Flora do Brasil (Forzza et al. 2015) e no banco de dados do Missouri Botanical Garden (Mobot 2015). 
Tabela 1. Espécies localmente raras selecionadas para a modelagem de nicho ecológico potencial na bacia do alto rio Madeira, sudoeste da Amazônia brasileira. Número de indivíduos amostrados no inventário realizado de acordo com o protocolo RAPELD (Moser et al. 2014).

\begin{tabular}{llc}
\hline Espécie & Família & $\begin{array}{c}\text { Número de } \\
\text { Indivíduos }\end{array}$ \\
\hline Moronobea coccinea Aubl. & Clusiaceae & 1 \\
Xylopia benthamii R.E.Fr. & Annonaceae & 1 \\
Vochysia biloba Ducke & Vochysiaceae & 1 \\
Buchenavia congesta Ducke & Combretaceae & 1 \\
Annona neoinsignis H.Rainer & Annonaceae & 1 \\
Semaphyllantheme gistocaula (K.Krause) L.Andersson & Rubiaceae & 2 \\
Nealchornea yapurensis Huber & & 1 \\
Brosimum parinarioides Ducke & Euphorbiaceae & 2 \\
Rauvolfia sprucei Müll.Arg. & & 2 \\
Chaunochiton kappleri (Sagot ex Engl.)Ducke & Olacaceae & 2 \\
Lacunaria jemmanii (Oliv.) Ducke & Quiinaceae & 2 \\
Qualea tessmannii Mildbr. & Vochysiaceae & 2 \\
Chrysophyllum colombianum (Aubrév.) T.D.Penn. & Sapotaceae & 2 \\
\hline
\end{tabular}




\subsubsection{Pontos de presença e variáveis ambientais}

Este trabalho está dividido em duas fases metodológicas. A primeira foi chamada de "pré-modelagem" e consistiu na criação de modelos de nicho para as 13 espécies. Esta pré-modelagem foi realizada com base nos pontos de presença das espécies obtidos do inventário florístico e depositados no Herbário Cen e no banco de dados de composição e estrutura da comunidade arbórea (Moser et al. 2014). Esta primeira fase teve como objetivo indicar possíveis áreas de ocorrência das espécies para a coleta de novos pontos de presença em campo e coletas de solos. Os dados desta etapa foram utilizados na segunda fase do trabalho, definida como "modelagem de nicho potencial final".

A pré-modelagem foi baseada em Siqueira et al. (2008), com adaptações às condições do bioma Amazônia e à escala local. Foram utilizadas 15 variáveis ambientais para a construção destes modelos, sendo que 11 foram determinadas por imagens de satélites do Normalized Difference Vegetation Index (NDVI) disponibilizadas pelo Serviço Geológico dos Estados Unidos (USGS). O NDVI mediu 11 meses da refletância espectral da vegetação, obtida pelo sensor MODIS (Moderate Resolution Imaging Spectroradiometer) com resolução espacial de $30 \mathrm{~m}$, entre os meses de janeiro e novembro do ano de 2013 (disponível em: http://earthexplorer.usgs.gov). Segundo Prates-Clark et al. (2008) os valores do NDVI são influenciados por mudanças sazonais e por fatores de influência sobre a vegetação, sendo expressivo em áreas heterogêneas.

As outras quatro variáveis foram obtidas pelas camadas derivadas dos Modelos Digitais de Elevação (MDE) disponibilizadas pelo TOPODATA (disponível em: http://www.webmapit.com.br/inpe/topodata) (Valeriano \& Rossetti 2012), sendo elas: elevação, aspecto, declividade e índice topográfico de umidade (TWI). O TWI foi obtido por função matemática utilizando a declividade e a área de acumulação do fluxo de água, sendo capaz de realçar o teor de saturação por água no solo, estimado o teor de umidade real (Sørensen et al. 2006). As imagens MDE fornecidas pelo TOPODATA são refinamentos geomorfométricos de $30 \mathrm{~m}$ dos dados originais da Shuttle Radar Topography Mission (SRTM), projeto liderado pela Agência Nacional de Inteligência Geoespacial e pela NASA (Rabus et al. 2003).

A pré-modelagem foi gerada no programa openModeller (Muñoz et al. 2009) com o algoritmo Environmental Distance que estima a distância linear (Distância Euclidiana) entre cada célula (pixel) das variáveis ambientais presentes na região da área de estudo e o centróide dos pontos de presença. Os modelos foram processados em imagens 
LANDSAT8 sensor OLI de 2014 em três cenas com composição natural e resolução espacial de $30 \mathrm{~m}$, obtidas no portal da USGS (disponível em: http://earthexplorer.usgs.gov). Os mapas oriundos dos modelos foram confeccionados a partir de técnicas de geoprocessamento por meio do software de Sistema de Informação Geográfica (SIG) ESRI® ArcGis 10.1.

A amostragem de novos dados em campo baseou-se no método de Avaliação Ecológica Rápida - AER (Sayre et al. 2003). As áreas amostradas de acordo com a AER foram selecionadas com base na pré-modelagem, preditas como áreas de presença potencial das espécies. Foram realizadas expedições ao local do estudo num total de 38 dias de campo, entre os meses de outubro de 2014 e abril de 2015. Foram feitas caminhadas aleatórias e registros da presença das espécies com georreferenciamento e por meio de formulários para descrição do ambiente. Além da amostragem dos indivíduos, foram coletadas amostras de solo de 0 a $20 \mathrm{~cm}$ de profundidade a cada novo registro de cada uma das 13 espécies. Não foram coletados pontos de ausência das espécies, pois a área de estudo é extensa e de difícil acesso. Quando não encontrada nenhuma das espécies do trabalho depois de caminhadas em todo local indicado pela predição, deslocava-se para nova área de ocorrência potencial. Todas as expedições contaram com o acompanhamento de parabotânico para auxílio na identificação taxonômica das espécies.

\subsection{Análise dos dados}

\subsubsection{Modelagem do nicho potencial final}

Para a modelagem do nicho potencial final buscou-se um refinamento da metodologia na escolha das variáveis ambientais e algoritmo, a fim de obter modelos com maior qualidade e melhor acurácia estatística. As amostras de solos foram enviadas para análise físico-química de acordo com o protocolo da Embrapa (1979) para areia, silte, argila, $\mathrm{pH}, \mathrm{Ca}^{2+}, \mathrm{Mg}^{2+}, \mathrm{K}^{+}$, soma de bases $(\mathrm{S})$, teor de matéria orgânica, $\mathrm{Al}^{3+}, \mathrm{H}+\mathrm{Al}, \mathrm{C}$ e $\mathrm{P}^{+}$. Para eliminar variáveis com valores elevados de correlação e selecionar aquelas mais significativas para a área, foram feitas Análise de Componentes Principais (PCA) e matriz de correlação no ambiente R (R Development Core Team 2015).

A seleção das variáveis também considerou indicações da literatura sobre a influência de fatores do ambiente sobre a distribuição de espécies arbóreas na Amazônia (Phillips et al. 2003; ter Steege et al. 2006; Ruokolainen et al. 2007; Coronado et al. 2009; 
Zuquim et al. 2012). Nestes estudos, a topografia e o solo, com destaque para as características de textura e para o teor de fertilidade, são os principais fatores determinísticos na composição e diferenciação florística na Amazônia, quando consideradas as escalas regionais e meso-escalas espaciais, como a área de influência da UHE Jirau (Moser et al. 2014).

Seguindo as premissas da literatura (Phillips et al. 2003; ter Steege et al. 2006; Ruokolainen et al. 2007; Coronado et al. 2009; Zuquim et al. 2012), as porcentagens de areia, silte, argila e soma de bases foram interpoladas por Krigagem Ordinária, transformando os dados pontuais em gradientes de valores espacializados com resolução de $30 \mathrm{~m}$. A Krigagem Ordinária consiste numa técnica da Geoestatística que utiliza a função de semi-variograma para ponderar os valores das variáveis, em escala local, que abrange toda a área a ser estudada (Goovaerts 1999). Foram utilizados 211 pontos de coleta de solos e os dados foram processados no programa ArcGis 10.1.

Para retratar a variação da vegetação no ano e de acordo com as formações florestais da área, foram utilizadas as mesmas cenas da pré-modelagem dos 11 meses do NDVI, entre janeiro e novembro de 2013 (Figueiredo et al. 2015; Saatchi et al. 2008). Embora o índice possa subestimar parcialmente a área de ocorrência potencial das espécies por desconsiderar as áreas florestadas anteriores ao ano de 2013, manteve-se esta variável em tempo atual pela dificuldade em obtê-la anteriormente às atividades transformadoras da paisagem na área de estudo.

A escolha das variáveis topográficas baseou-se no conhecimento da paisagem local, em que a altitude e a declividade apresentam variações que contribuem na composição de diferentes ambientes, e que potencialmente pode influenciar na distribuição das espécies (Clark et al. 1999). Alguns autores defendem que a redução do número de descritores ambientais por meio de técnicas para eliminar variáveis com maiores valores de correlação para a modelagem pode levar à perda de informações importantes, que dificulta a interpretação dos modelos de nicho, subestima os resultados e enfraquece o desempenho dos modelos (Hijmans \& Graham 2006; Dormann 2007; Ramírez-Villegas et al. 2010). Os mesmos autores defendem de que a correlação entre variáveis pode apresentar valores muito diferentes no tempo e no espaço. No presente estudo, a redução de variáveis ambientais, com a utilização de apenas quatro cenas do NDVI, além de altitude, declividade e quatro variáveis de solos, resultou em modelos com desempenho reduzido e baixos valores de acurácia. Desta forma, as quatro variáveis relacionadas ao solo, 
juntamente com as 11 cenas do NDVI e as duas derivadas do MDE (altitude e declividade) resultaram num total de 17 descritores ambientais.

O algoritmo escolhido para a modelagem final foi o GARP- Genetic Algorithm for Rule-set Production (Stockwell \& Noble 1992; Stockwell \& Peters 1999), executado também no framework open Modeller (Muñozet al. 2009). O algoritmo GARP é indicado em modelagem para o uso de apenas dados de presença das espécies, predizendo pontos de pseudo-ausências na projeção do nicho potencial (Stockwell \& Peters 1999; Anderson et al. 2003; Elith et al. 2006; Franklin 2009). Este algoritmo apresenta resultados com baixo número de pontos de ocorrência, como em predições de nichos de populações pouco coletadas, pouco abundantes ou raras (Pearson et al. 2007; Siqueira et al. 2008; De Marco \& Siqueira 2009).

O GARP adota um conjunto de regras a partir de ferramentas de inferência que representam possíveis relações multivariadas (regressões logísticas, regressões categóricas e regressões múltiplas) entre a ocorrência das espécies e as variáveis ambientais (Stockwell \& Peters 1999; Peterson \& Cohoon 1999). Os pontos de ocorrência são divididos pelo algoritmo em dados de "treino" e "teste" e a partir dos dados de treino uma sequência de regras é desenvolvida, as quais as melhores são selecionadas para incorporar a predição (Peterson \& Kluza 2005; Peterson \& Papes 2007). A modelagem final obteve melhores resultados com $75 \%$ das amostras para treino e $25 \%$ para teste.

A validação dos modelos utilizou as estatísticas da matriz de confusão, como o índice Kappa (Cohen's Kappa Statistic) e o valor AUC, que correspondente a integral da área sob a curva de características de funcionamento do receptor (curva ROC) (Fielding \& Bell 1997; Manel et al. 2001; Allouche et al. 2006; MacPherson \& Jetz 2007). A matriz de confusão indica a proporção dos locais previstos corretamente e a sensibilidade e a especificidade da predição (Anderson et al. 2002; Anderson et al. 2003; Allouche et al. 2006). A sensibilidade se refere à proporção das presenças observadas que são previstas e quantifica os erros de omissão (Allouche et al. 2006). Segundo os mesmos autores, a especificidade indica a proporção das ausências observadas que também são previstas e quantifica os erros de comissão.

Para melhorar o desempenho dos modelos a partir dos dados com apenas a ocorrência das espécies foi utilizado o GARP with Best subsets - Desktop implementation, o implemento do algoritmo original realizado por Anderson et al. (2003). Os mesmos 
autores indicam que esta versão do GARP equilibra a omissão e comissão da espécie na área e gera 'pseudo-ausências' ("backgroud") de acordo com a quantidade dos dados de presença utilizados nos modelos para cada espécie. Além disso, o GARP with Best subsets diminui a variabilidade típica de modelos genéticos que dificultam a interpretação para dados assimétricos (apenas pontos de presença) e utiliza a acurácia dos modelos gerados a partir da matriz de confusão inserindo as 'pseudo-ausências' geradas pelo algoritmo (Anderson et al. 2003).

O índice Kappa gerado pela matriz de confusão e utilizado na acurácia dos modelos mede a proporção de todos os casos possíveis de presença ou ausência previstos corretamente depois de contabilizar o acaso, variando entre -1 e 1 , onde 1 indica a perfeita concordância com o melhor desempenho do modelo (Manel et al. 2001; Allouche et al. 2006). O AUC, também usado na validação, é uma integral da curva ROC, com valores entre 0 e 1 , onde os valores mais próximos a 1 correspondem aos modelos com melhores resultados (MacPherson \& Jetz 2007). A curva ROC traça a sensibilidade versus especificidade ao longo de um limite de classificação dos dados, determinados como thresholds dependentes (Hanley \& McNeil 1982; MacPherson \& Jetz 2007). Para a adequação da acurácia, utilizou-se o limite de classificação (threshold) dependente de $20 \%$ indicado pela literatura para poucos dados de ocorrência (Siqueira et al. 2008; Freeman \& Moisen 2008; Franklin 2009).

\subsubsection{Determinação das áreas de impacto e porcentagens de perda de nicho}

Os principais impactos ocorrentes no local de estudo são o "alagamento da UHE de Jirau" e o "desmatamento". Neste último consideramos a retirada de vegetação para a construção da UHE de Jirau, para agropecuária, estradas, linhas de transmissão e urbanização. Os impactos foram determinados por classificação de imagens LANDSAT8 sensor OLI em três cenas, com resolução espacial de $30 \mathrm{~m}$. As imagens utilizadas para determinar a áreas dos impactos foram de agosto de 2014, período de maior enchimento da barragem após a construção, em que o rio atingiu a cota de $90 \mathrm{~m}$. A classificação e tratamento das imagens foram realizadas no software ArcGis 10.1. 
Os modelos de nicho ecológicos finais foram transformados em polígonos de presença na área de estudo. Por meio da ferramenta Calculate Geometry do ArcGis 10.1 as ocorrências potenciais foram quantificadas em metros quadrados para cada espécie. A classificação que determinou os impactos gerou imagens da área total de cada impacto no local do estudo. A partir do mesmo ambiente do ArcGis 10.1 realizou-se a interseção entre a imagem de cada impacto sobre as áreas de distribuição potencial das espécies pela ferramenta Extraction, o que possibilitou calcular a perda de áreas estimadas em presença.

\section{RESULTADOS}

\subsection{Pré-modelagem e AER}

A pré-modelagem, com base no algoritmo Environmental Distance, auxiliou de forma variada na coleta de novos registros para cada espécie (Figura 2). A amplitude desses registros variou entre cinco e 10 indivíduos e as espécies Vochysia biloba Ducke, Xylopia benthamii R.E.Fr. e Moronobea coccinea Aubl. obtiveram as menores ocorrências (Tabela 2). 


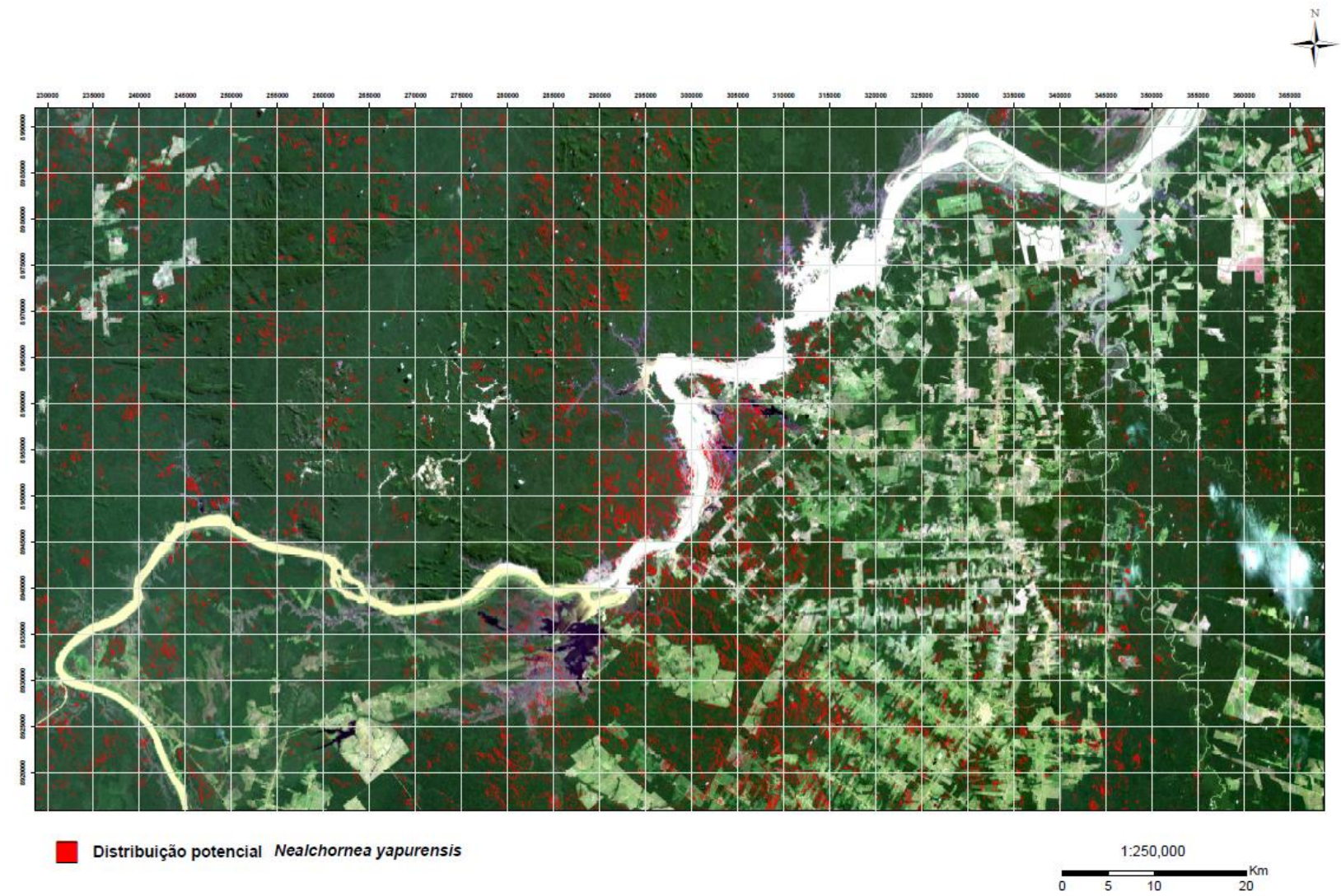

Figura 2. Exemplo do mapa gerado pela pré-modelagem do nicho potencial de Nealchornea yapurensis Huber na área de influência direta e indireta da UHE de Jirau, na bacia do alto rio Madeira, sudoeste da Amazônia brasileira, Brasil. A distribuição potencial da espécie está representada em vermelho (Imagem Landsat8 de agosto de 2014, UTM zona 20S, DATUM: WGS 84). 
Tabela 2. Número de indivíduos coletados a partir da pré-modelagem e caracterização dos ambientes de ocorrência das espécies localmente raras na bacia do alto rio Madeira, sudoeste da Amazônia brasileira, Brasil.

\begin{tabular}{ccc}
\hline Espécie & $\begin{array}{c}\mathbf{N}^{0} \text { de indivíduos } \\
\text { coletados }\end{array}$ & $\begin{array}{c}\text { Ambientes característicos de } \\
\text { ocorrência }\end{array}$
\end{tabular}

Moronobea coccinea Aubl. 5

Xylopia benthamii R.E.Fr. 7

Vochysia biloba Ducke

Buchenavia congesta Ducke

Semaphyllanthe megistocaula (K.Krause) L. Andersson

Nealchornea yapurensis Huber

Rauvolfia sprucei Müll.Arg.
7

Floresta de Terra Firme, Florestas Ombrófilas Densa e Aberta, terreno plano, solos areno/argilosos

Floresta de Terra Firme, Floresta Ombrófila Aberta, terreno plano, solos arenosos.

\section{Floresta de Terra Firme, Floresta Ombrófila Aberta, terreno ondulado, áreas com afloramentos rochosos, solos areno/argilosos.}

Floresta Ombrófila Aberta, encosta com afloramentos rochosos, solos arenosos.

Floresta Ombrófila Aberta, encostas íngremes com afloramentos rochosos, vertentes.
Floresta de Terra Firme, Floresta Ombrófila Aberta, terreno plano, solos areno/argilosos.

Floresta Ombrófila Aberta, vertentes e terreno suave ondulado, solos arenosos.

Floresta Ombrófila Aberta, terrenos ondulados, encostas com afloramentos rochosos, solos areno/argilosos.

Floresta de Terra Firme, Floresta Ombrófila Aberta, relevos acidentados, solos arenosos. 
Tabela2, cont. Continua...

Chaunochiton kappleri (Sagot ex Engl.) Ducke

Lacunaria jenmanii (Oliv.) Ducke

Qualea tessmannii Mildbr.

Chrysophyllum colombianum (Aubrév.)

T.D.Penn.
10

10

10

10
Floresta de Terra Firme, Florestas

Ombrófilas Aberta e Densa, terrenos planos/ ondulados, solos areno/argilosos.

Floresta Ombrófila Aberta, encostas com afloramentos rochosos, margens de córregos, solos arenosos.

Floresta de Terra Firme, Floresta Ombrófila Aberta, terrenos planos/ ondulados, áreas com afloramentos rochosos, solos areno/argilosos.

Floresta de Terra Firme, Florestas Ombrófilas Aberta e Densa, terrenos ondulados, solos siltosos/areno/argilosos.

\subsection{Modelagem do Nicho Potencial Final}

Os mapas com os teores de argila, areia, silte e soma de bases gerados pela Krigagem Ordinária possibilitou representar o gradiente potencial destas variáveis na área de estudo (Figuras 3, 4, 5 e 6). 


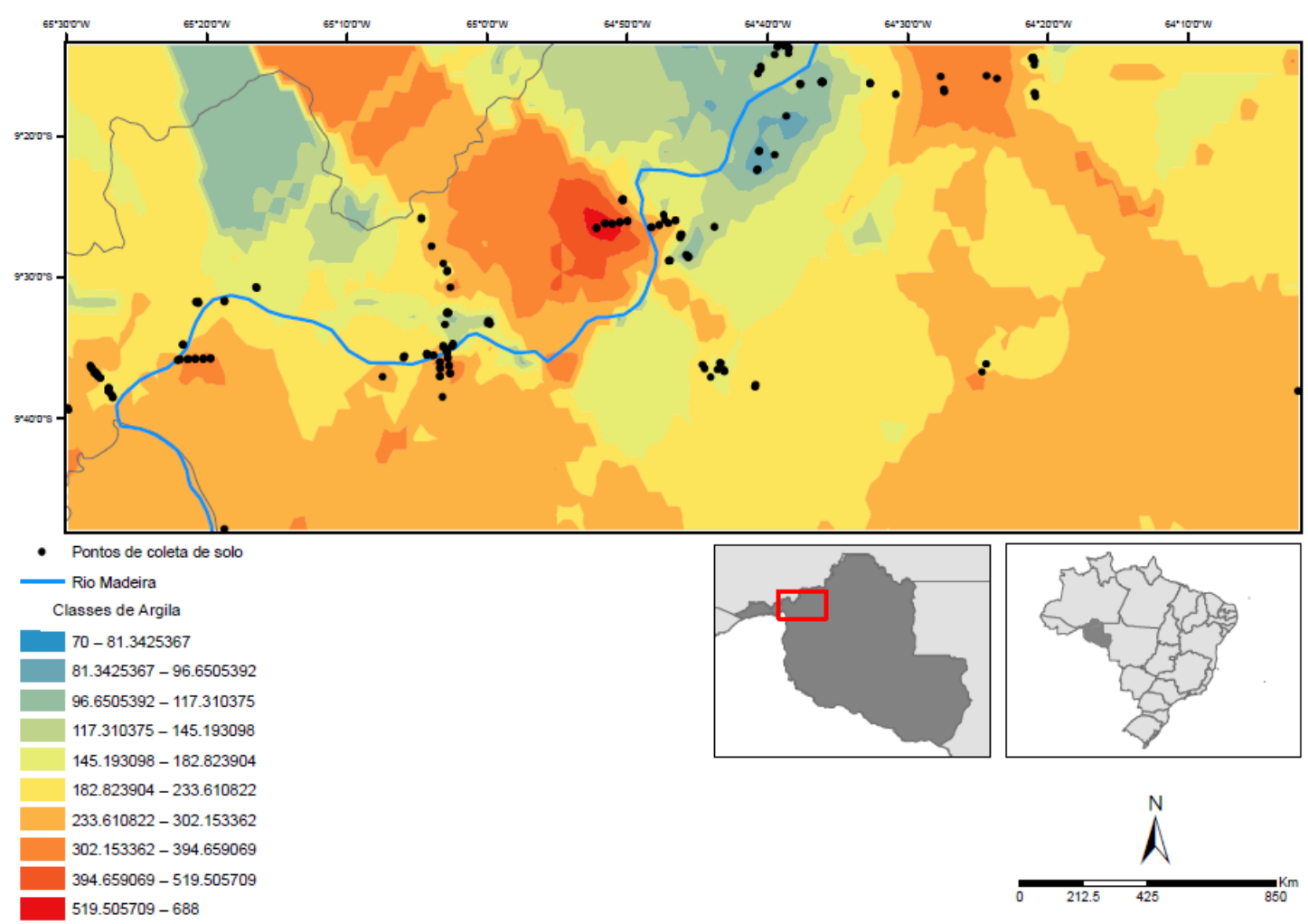

Figura 3. Conteúdo de argila $(\mathrm{g} / \mathrm{Kg})$ na bacia do alto rio Madeira, sudoeste da Amazônia brasileira, Brasil.

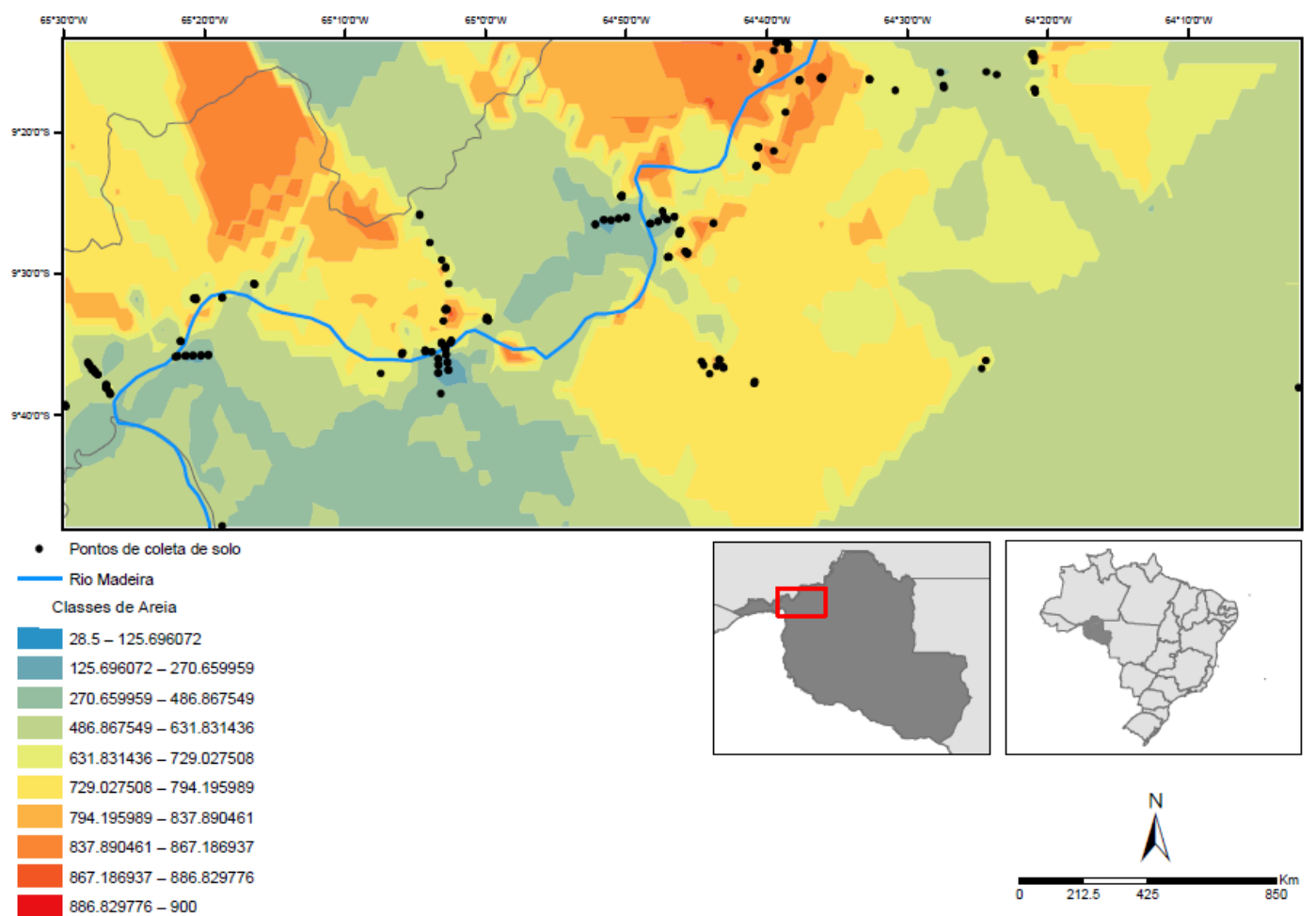

Figura 4. Conteúdo de areia $(\mathrm{g} / \mathrm{Kg})$ na bacia do alto rio Madeira, sudoeste da Amazônia brasileira, Brasil. 


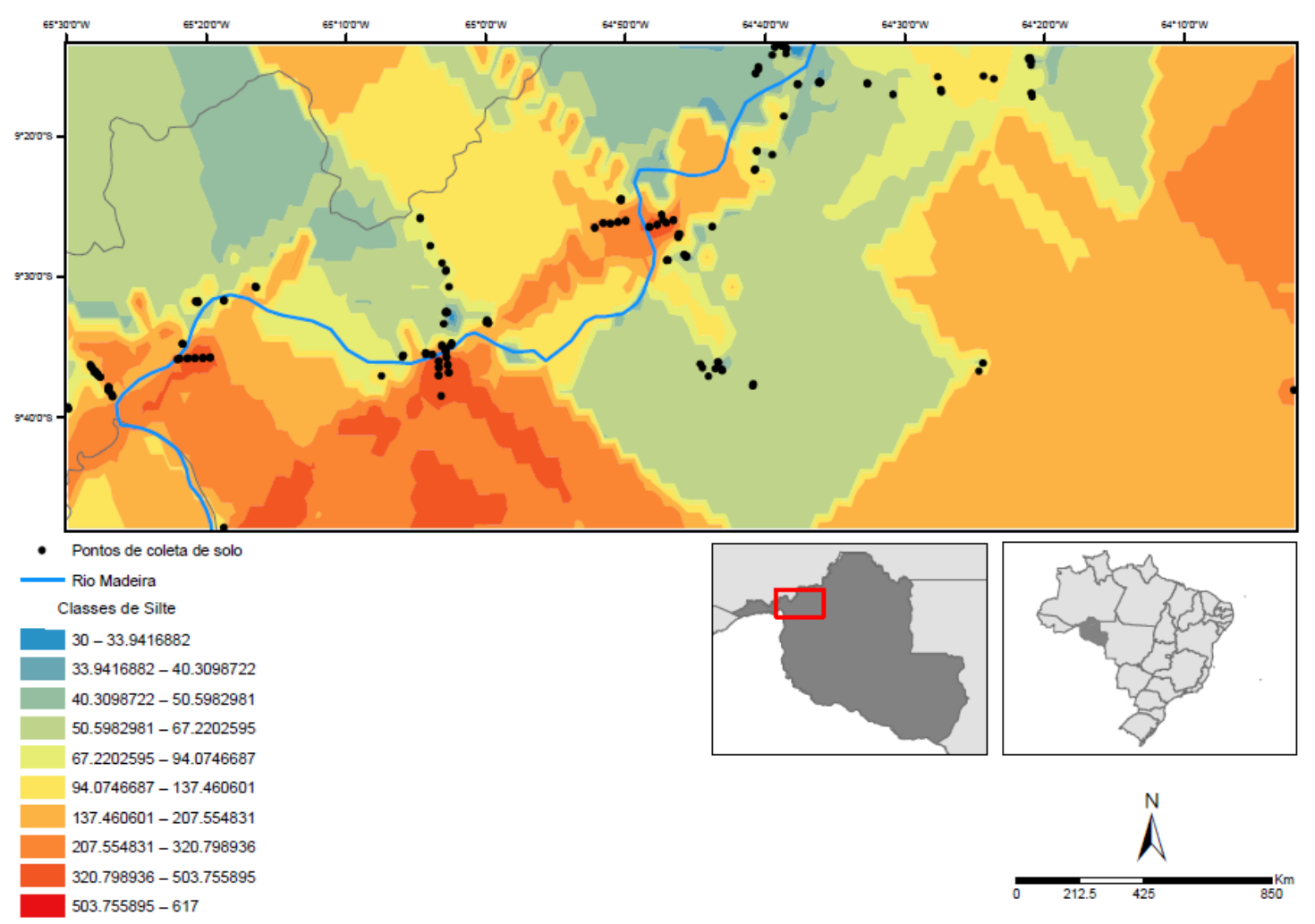

Figura 5. Conteúdo de silte $(\mathrm{g} / \mathrm{Kg})$ na bacia do alto rio Madeira, sudoeste da Amazônia brasileira, Brasil. 


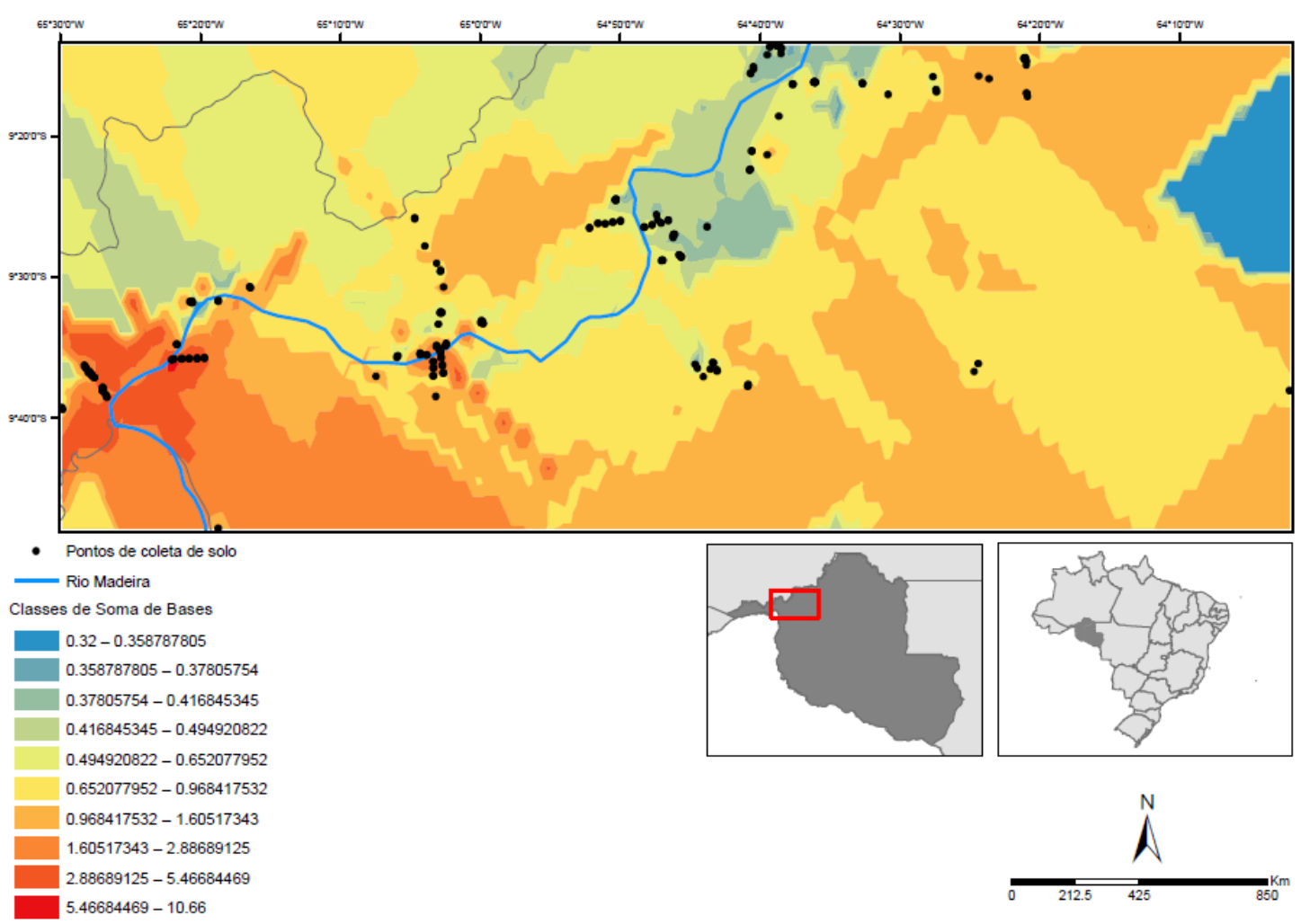

Figura 6. Conteúdo de soma de bases $(\mathrm{cmolc} / \mathrm{kg})$ na bacia do alto rio Madeira, sudoeste da Amazônia brasileira, Brasil.

A acurácia dos modelos apontou desempenhos significativos dos valores do índice AUC e Kappa (Tabela 3). A sensibilidade foi ponderada considerando o máximo das presenças observadas na previsão para todas as espécies, o que equivaleu os erros de omissão a zero. Apesar de utilizar 'pseudo-ausências' na matriz de confusão para a acurácia dos modelos, o GARP with Best subsets não avaliou a especificidade, ou seja, a proporção das ausências observadas previstas e os erros em comissão, que mede a inclusão de mais classes de previsão das ocorrências. 
Tabela 3. Estatísticas de validação da modelagem de nicho potencial final. Valores de AUC (área sob a curva de características de funcionamento do receptor) e Kappa variam entre 0 e 1.

\begin{tabular}{lcc}
\hline Espécie & AUC & Kappa \\
\hline Moronobea coccinea Aubl. & 1,00 & 0,99 \\
Xylopia benthamii R.E.Fr. & 0,98 & 0,98 \\
Vochysia biloba Ducke & 0,92 & 0,91 \\
Buchenavia congesta Ducke & 0,98 & 0,97 \\
Annona neoinsignis H.Rainer & 0,98 & 0,98 \\
Semaphyllanthe megistocaula (K.Krause) L.Andersson & 1,00 & 0,99 \\
Nealchornea yapurensis Huber & 0,99 & 0,99 \\
Brosimum parinarioides Ducke & 1,00 & 0,99 \\
Rauvolfia sprucei Müll.Arg. & 0,99 & 0,99 \\
Chaunochiton kappleri (Sagot ex Engl.) Ducke & 0,99 & 0,99 \\
Lacunaria jenmanni (Oliv.) Ducke & 0,99 & 0,98 \\
Qualea tessmannii Mildbr. & 0,92 & 0,92 \\
Chrysophyllum colombianum (Aubrév.) T.D.Penn. & 1,00 & 0,99 \\
\hline
\end{tabular}




\subsection{Determinação das áreas de impacto e porcentagens de perda de áreas de distribuição potenciais}

A modelagem de nicho potencial com o algoritmo GARP gerou mapas das áreas de distribuição potencial das espécies. As imagens dos impactos do "alagamento da UHE de Jirau" e do "desmatamento" foram inseridas nos modelos de nicho ecológico final de cada espécie para compor mapas que indicam as áreas de ocorrências potenciais na área de estudo e os respectivos impactos potenciais (Figuras 7, 8, 9, 10, 11, 12, 13, 14, 15, 16, 17, 18 e 19).

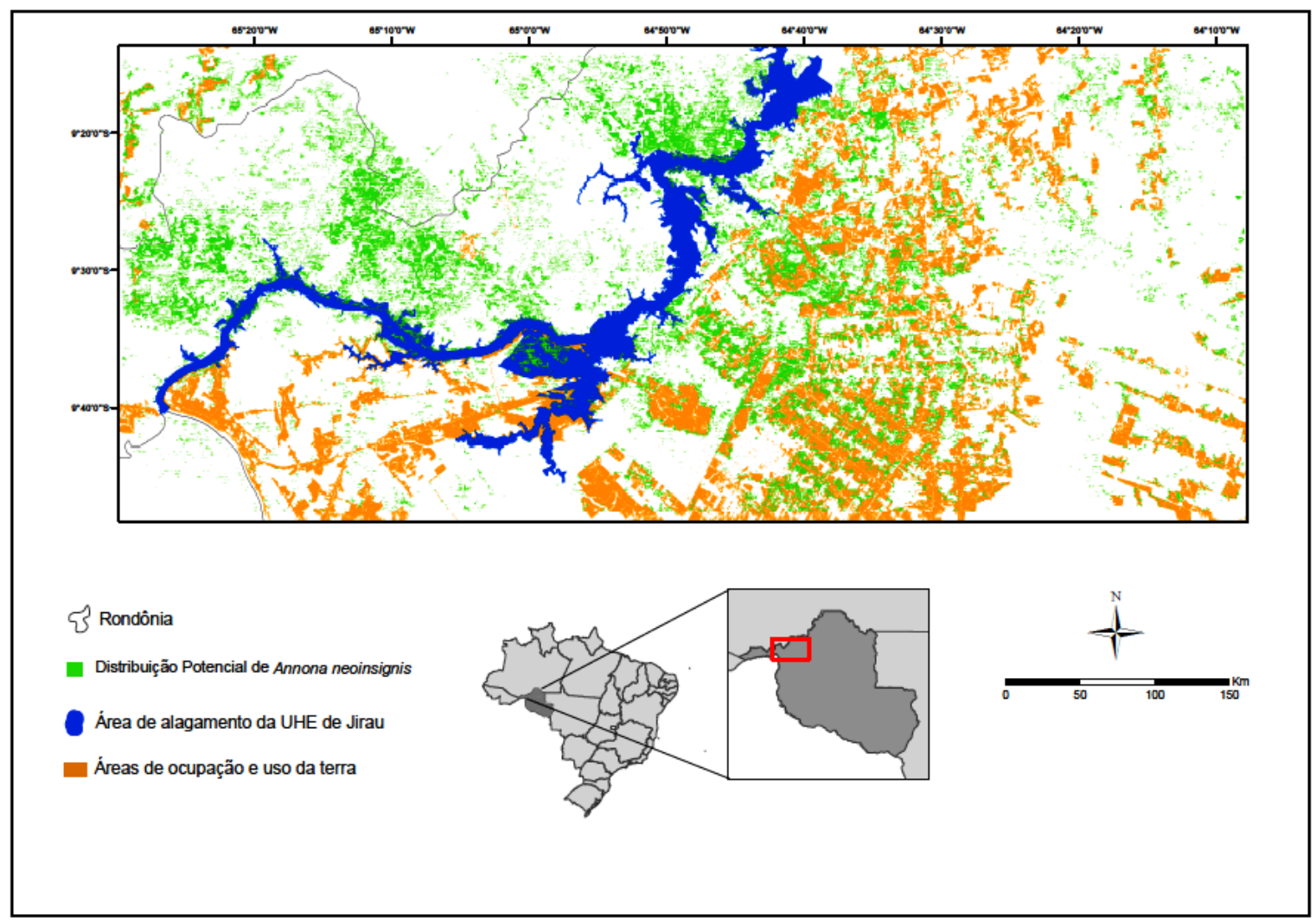

Figura 7. Área de distribuição potencial de Annona neoinsignis H, Rainer e os impactos 'alagamento da UHE de Jirau' e ‘desmatamento’ na bacia do alto rio Madeira, sudoeste da Amazônia brasileira, Brasil (Imagem de agosto de 2014, UTM zona 20S, DATUM: WGS 84). 


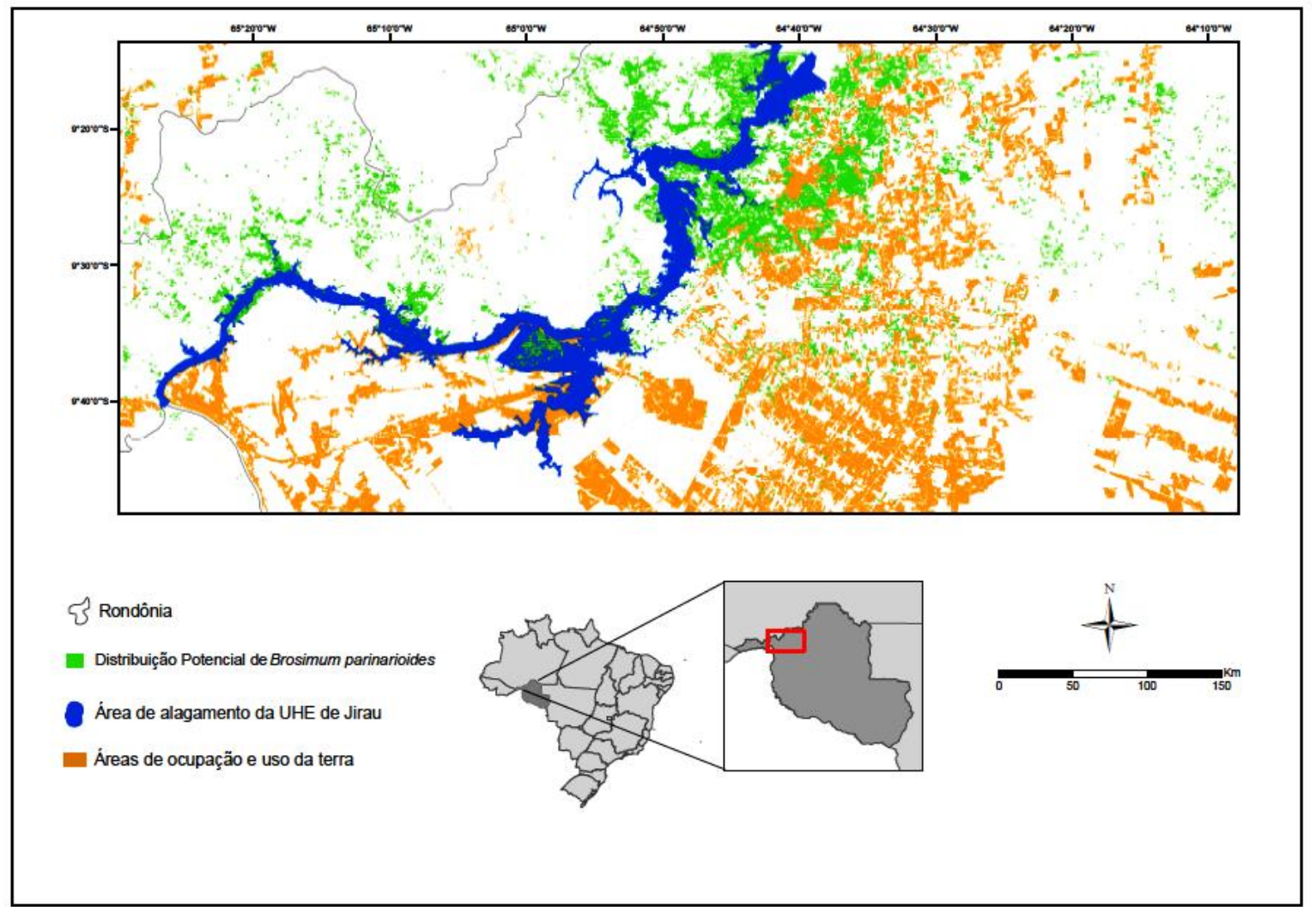

Figura 8. Área de distribuição potencial de Brosimum parinarioides Ducke e os impactos 'alagamento da UHE de Jirau' e 'desmatamento' na bacia do alto rio Madeira, sudoeste da Amazônia brasileira, Brasil (Imagem de agosto de 2014, UTM zona 20S, DATUM: WGS 84). 


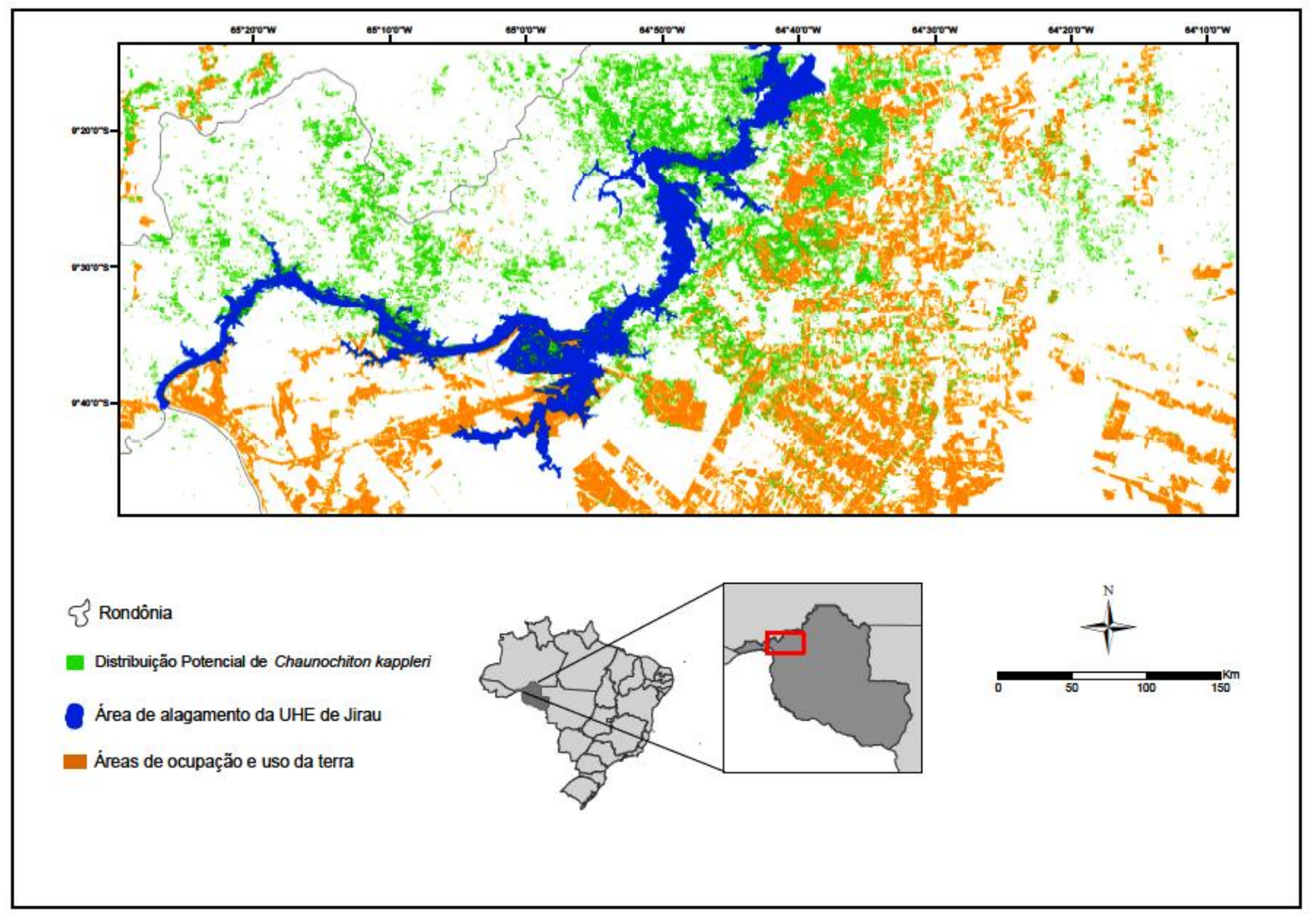

Figura 9. Área de distribuição potencial de Chaunochiton kappleri (Sagot ex Engl,) Ducke e os impactos 'alagamento da UHE de Jirau' e ‘desmatamento' na bacia do alto rio Madeira, sudoeste da Amazônia brasileira, Brasil (Imagem de agosto de 2014, UTM zona 20S, DATUM: WGS 84). 


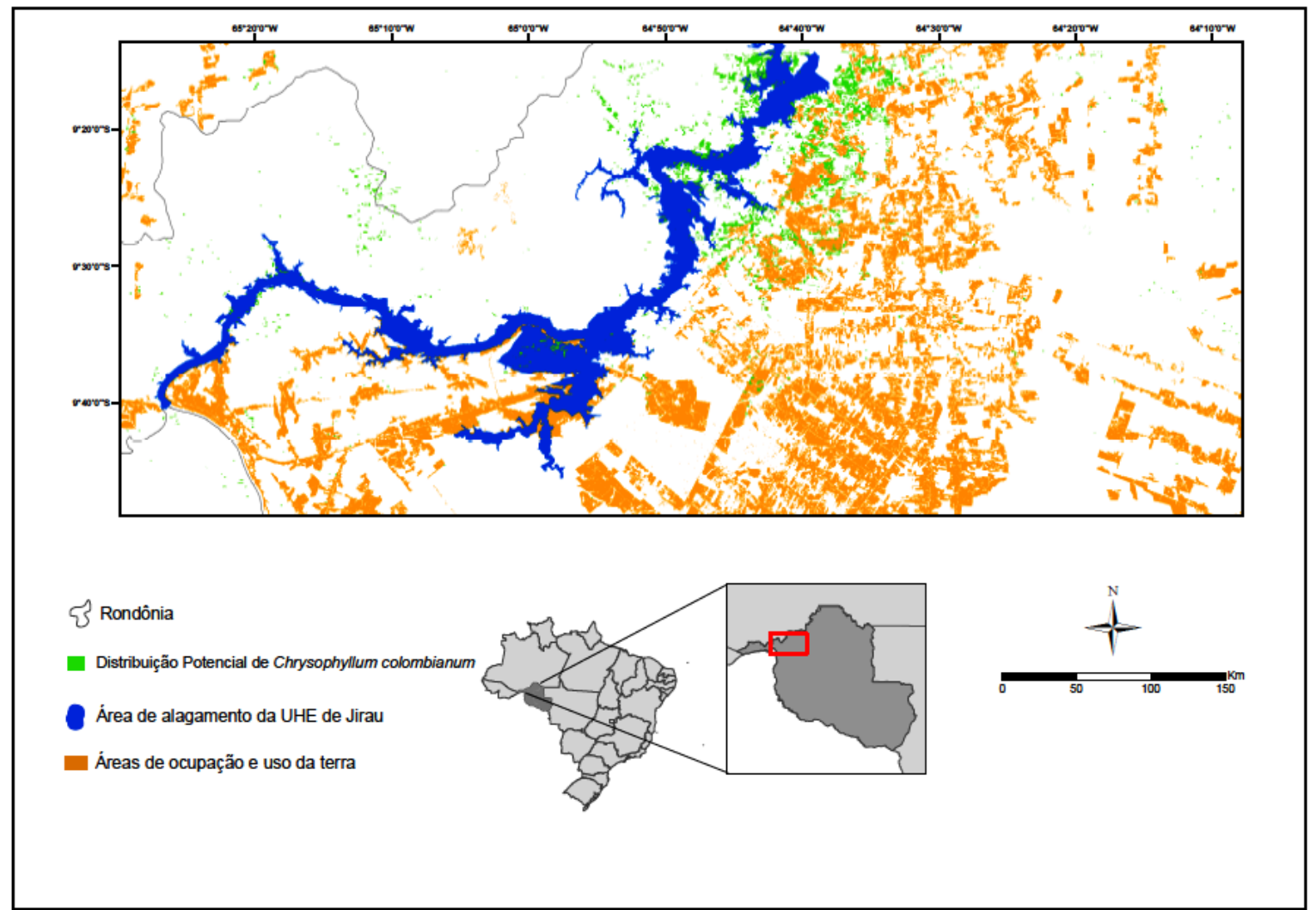

Figura 10. Área de distribuição potencial de Chrysophyllum colombianum (Aubrév.) T.D.Penn, e os impactos 'alagamento da UHE de Jirau' e ‘desmatamento' na bacia do alto rio Madeira, sudoeste da Amazônia brasileira, Brasil (Imagem de agosto de 2014, UTM zona 20S, DATUM: WGS 84). 


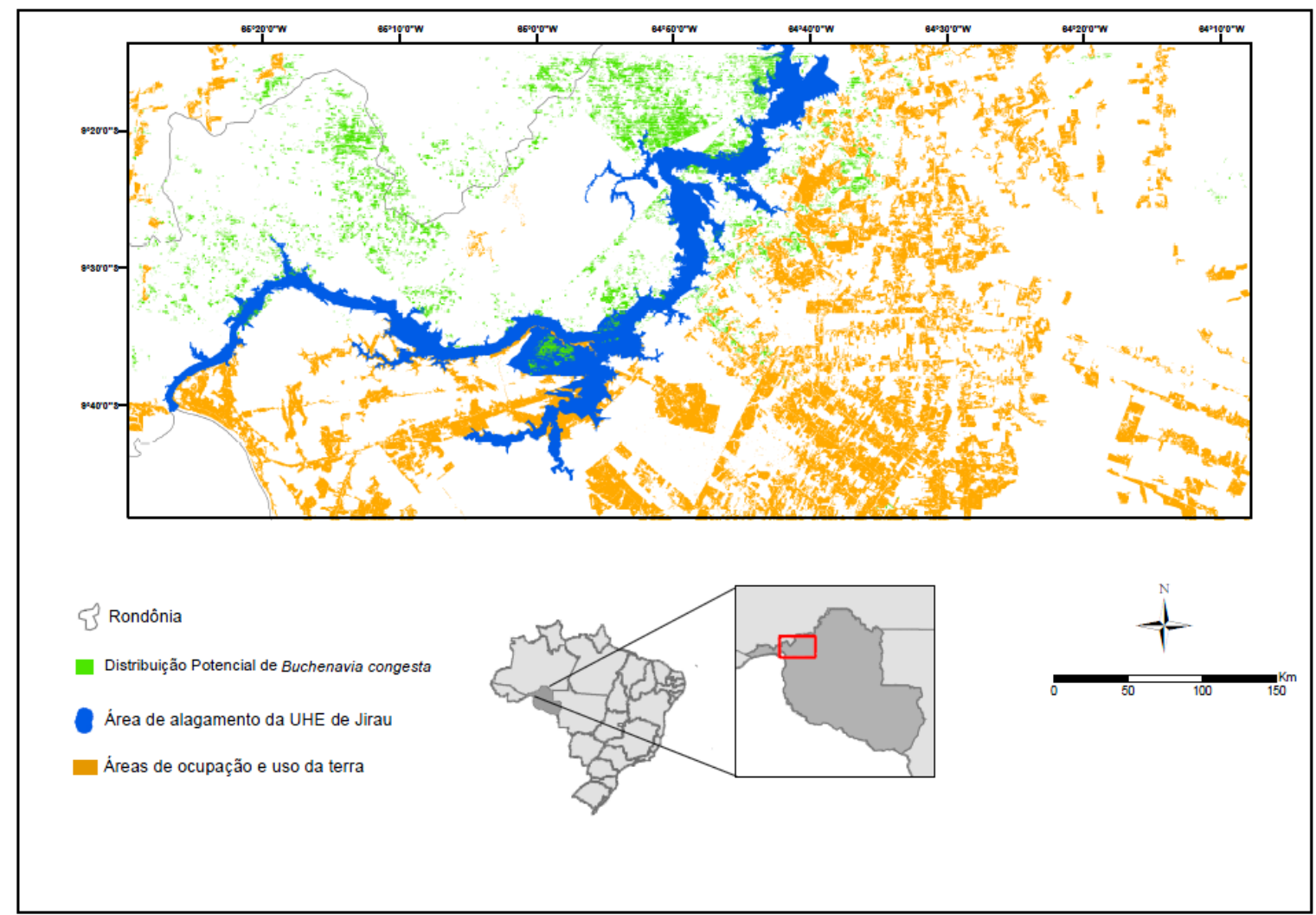

Figura 11. Área de distribuição potencial de Buchenavia congesta Ducke e os impactos 'alagamento da UHE de Jirau' e 'desmatamento' na bacia do alto rio Madeira, sudoeste da Amazônia brasileira, Brasil (Imagem de agosto de 2014, UTM zona 20S, DATUM: WGS 84). 


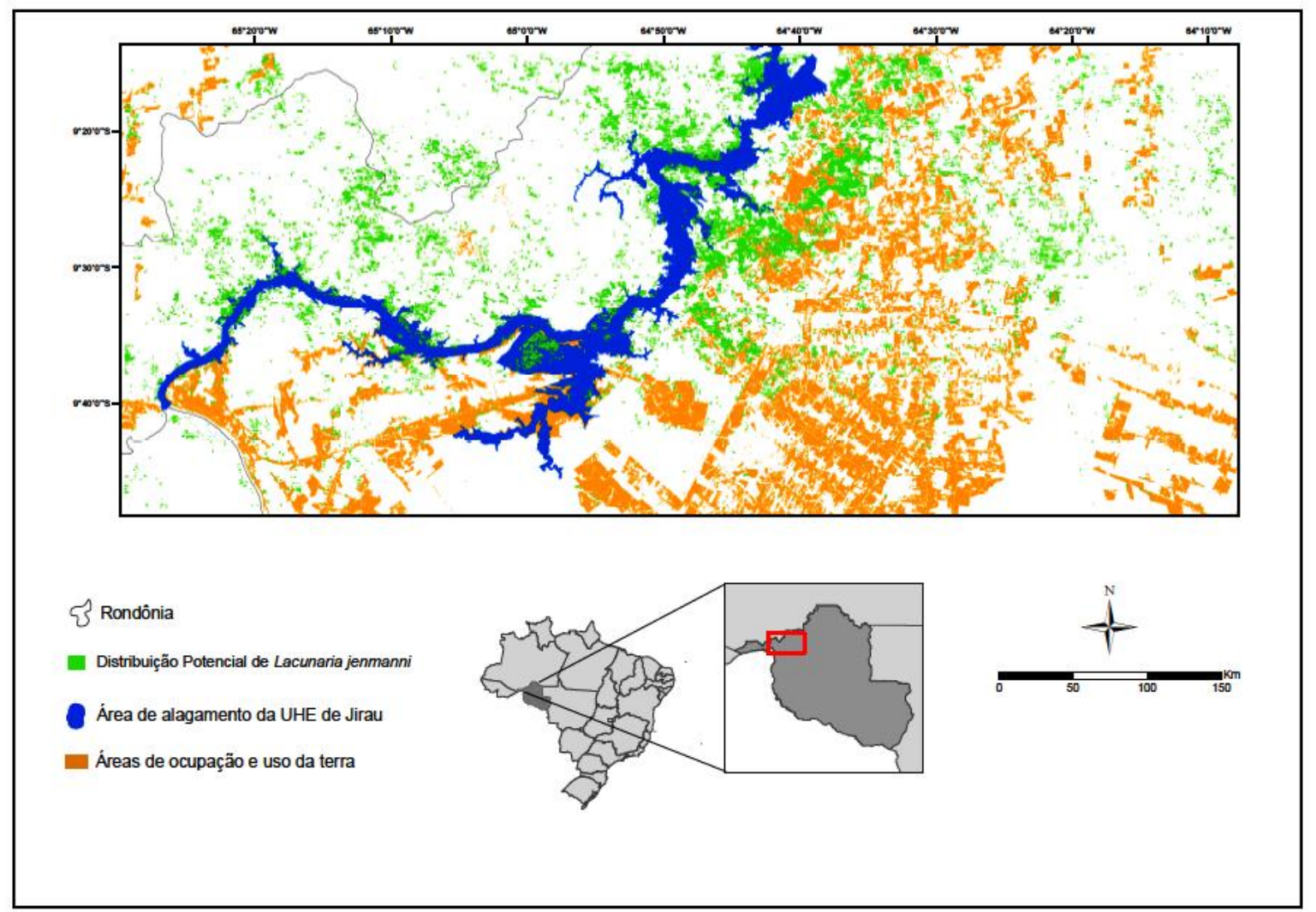

Figura 12. Área de distribuição potencial de Lacunaria jenmanni (Oliv,) Ducke e os impactos 'alagamento da UHE de Jirau' e 'desmatamento' na bacia do alto rio Madeira, sudoeste da Amazônia brasileira, Brasil (Imagem de agosto de 2014, UTM zona 20S, DATUM: WGS 84). 


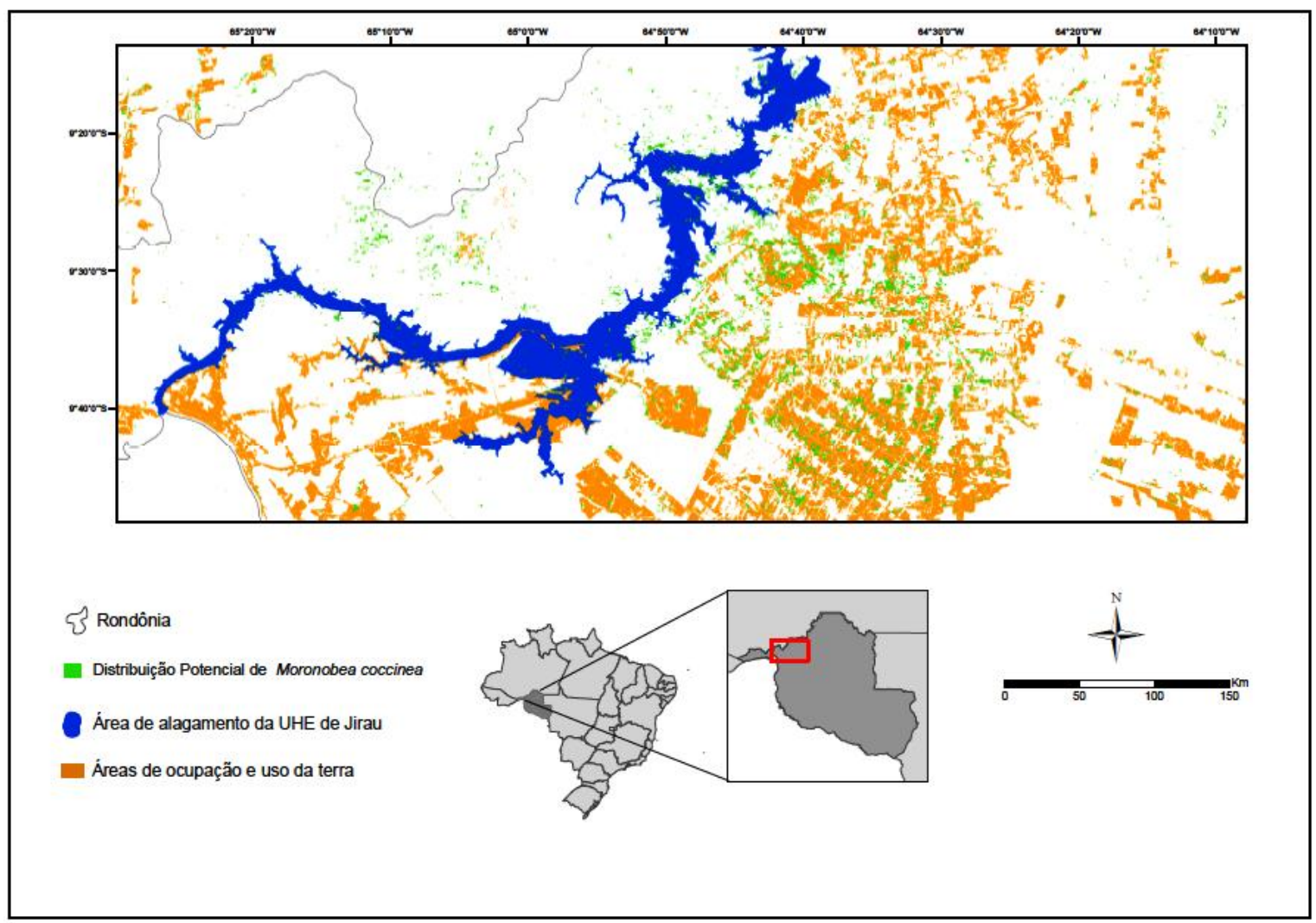

Figura 13. Área de distribuição potencial de Moronobea coccinea Aubl, e os impactos 'alagamento da UHE de Jirau' e 'desmatamento' na bacia do alto rio Madeira, sudoeste da Amazônia brasileira, Brasil (Imagem de agosto de 2014, UTM zona 20S, DATUM: WGS 84). 


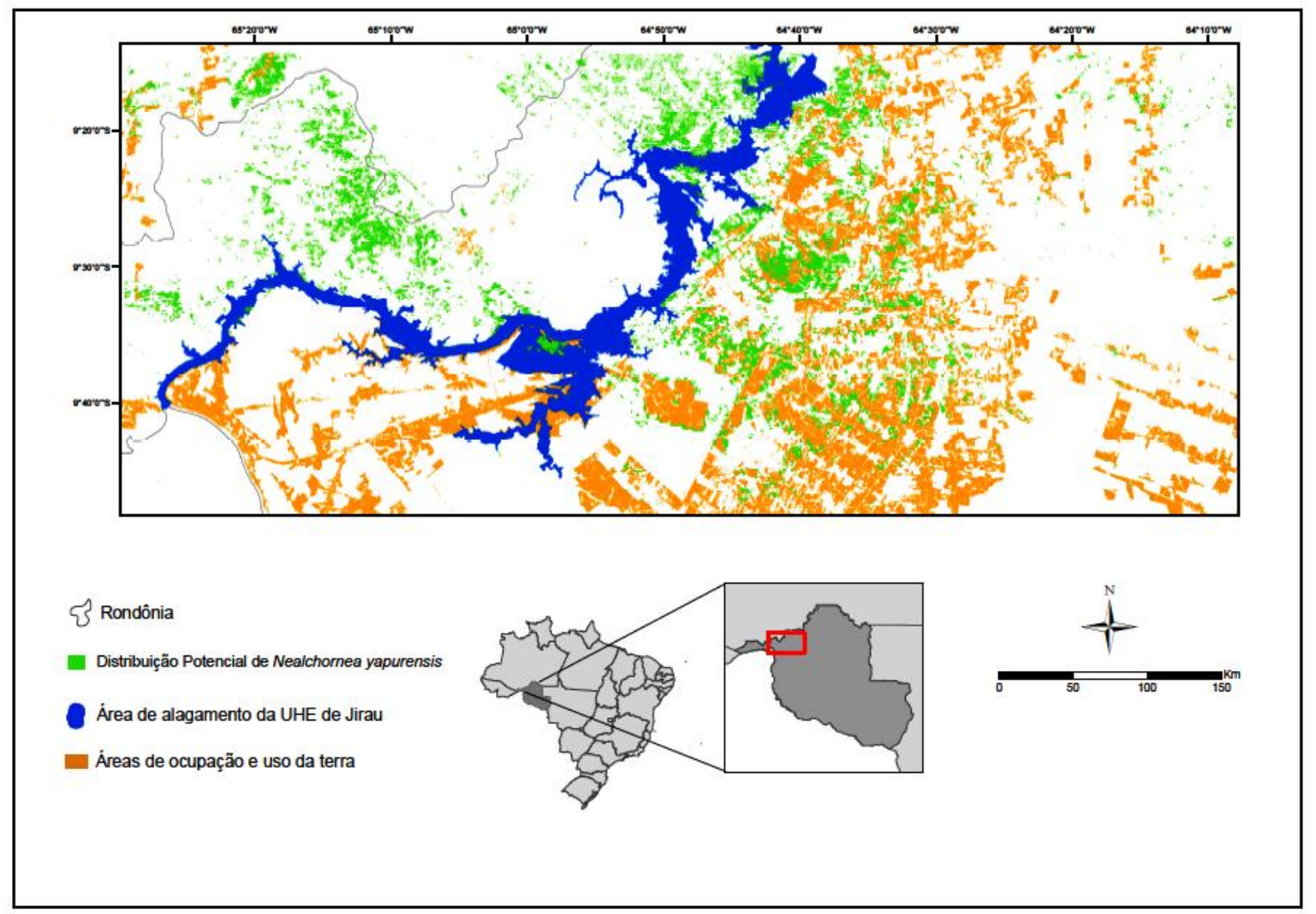

Figura 14. Área de distribuição potencial de Nealchornea yapurensis Huber e os impactos 'alagamento da UHE de Jirau' e 'desmatamento' na bacia do alto rio Madeira, sudoeste da Amazônia brasileira, Brasil (Imagem de agosto de 2014, UTM zona 20S, DATUM: WGS 84). 


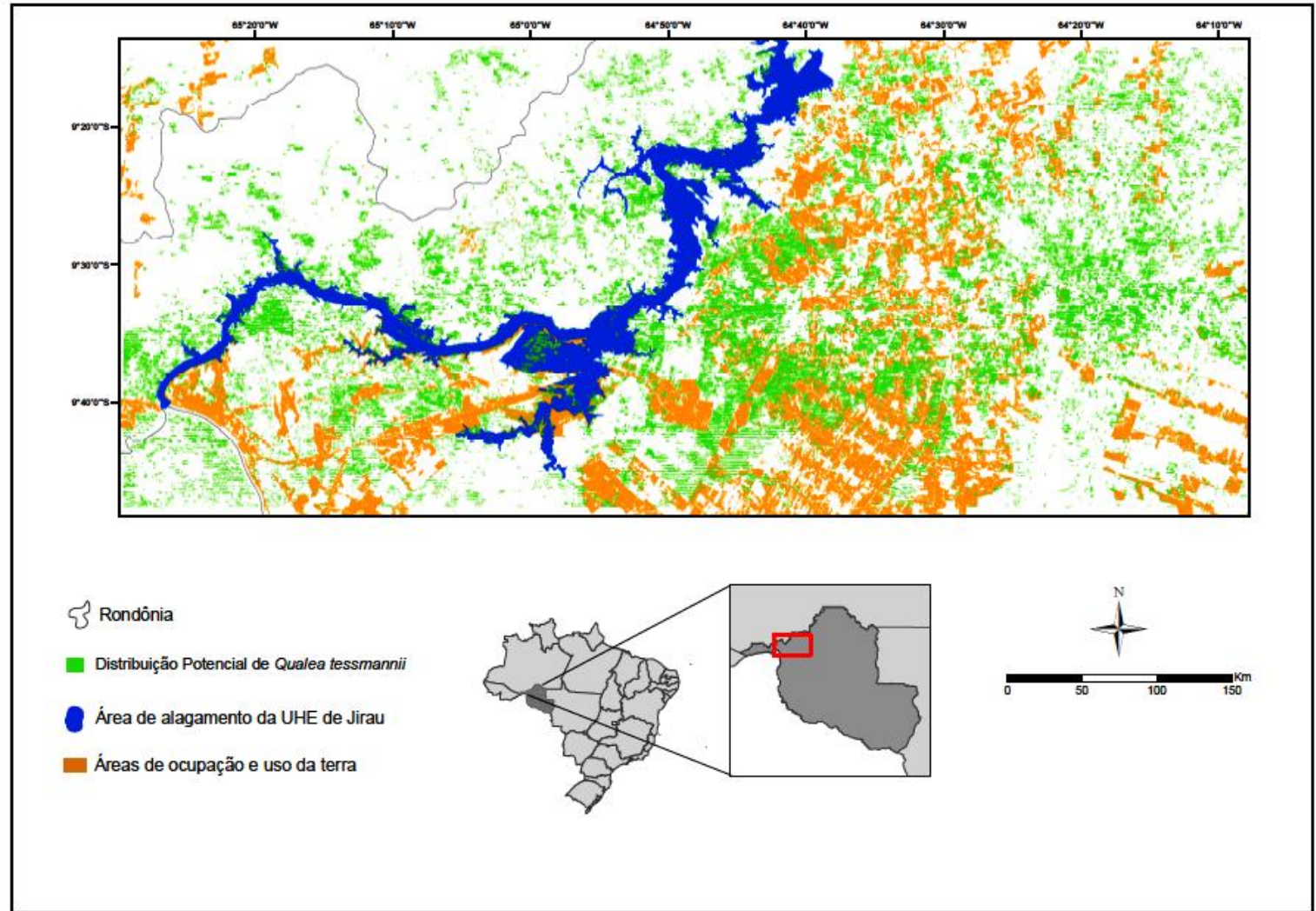

Figura 15. Área de distribuição potencial de Qualea tessmannii Mildbr, e os impactos 'alagamento da UHE de Jirau' e 'desmatamento' na bacia do alto rio Madeira, sudoeste da Amazônia brasileira, Brasil (Imagem de agosto de 2014, UTM zona 20S, DATUM: WGS 84). 


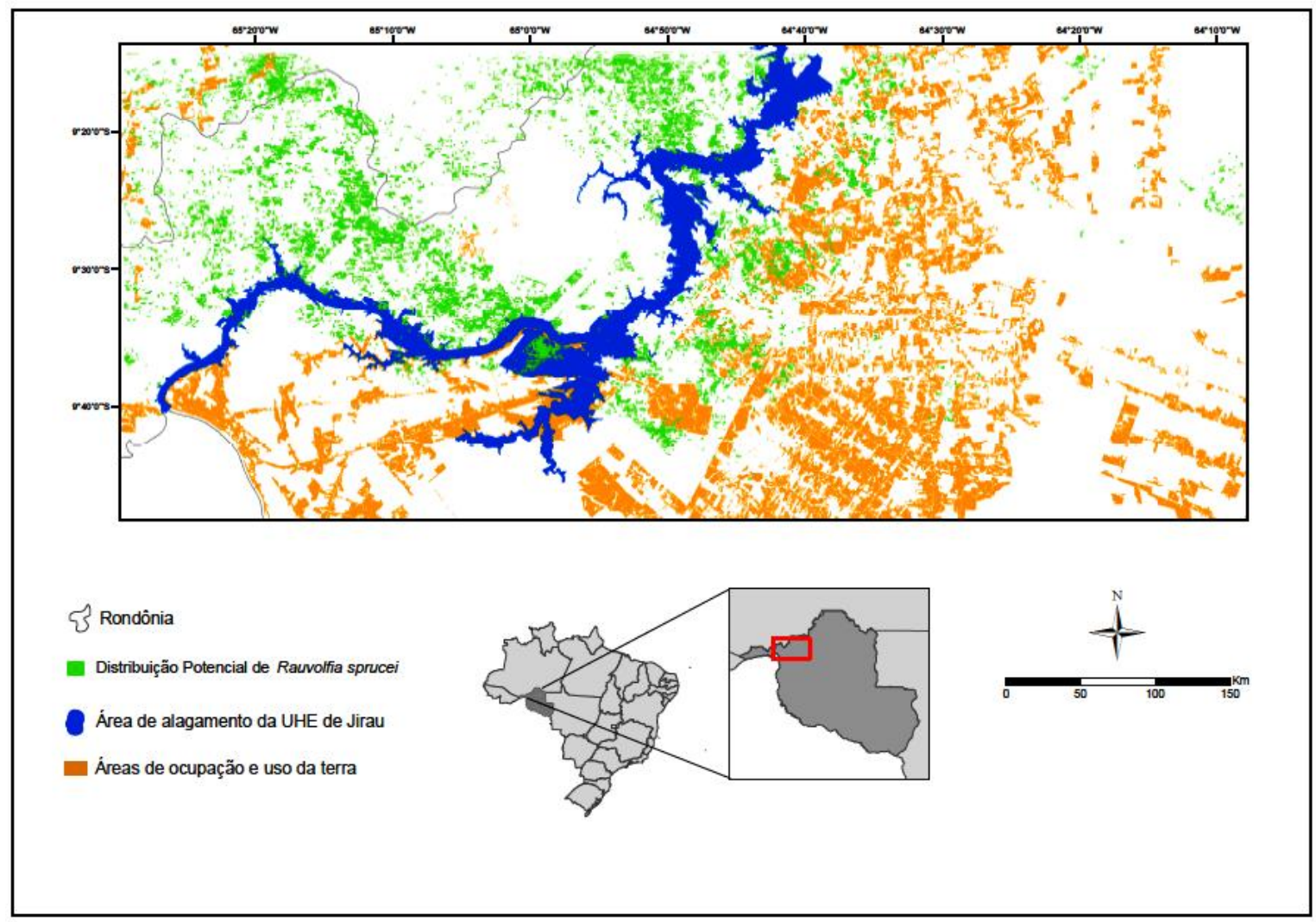

Figura 16. Área de distribuição potencial de Rauvolfia sprucei Müll,Arg, e os impactos 'alagamento da UHE de Jirau' e 'desmatamento' na bacia do alto rio Madeira, sudoeste da Amazônia brasileira, Brasil (Imagem de agosto de 2014, UTM zona 20S, DATUM: WGS 84). 


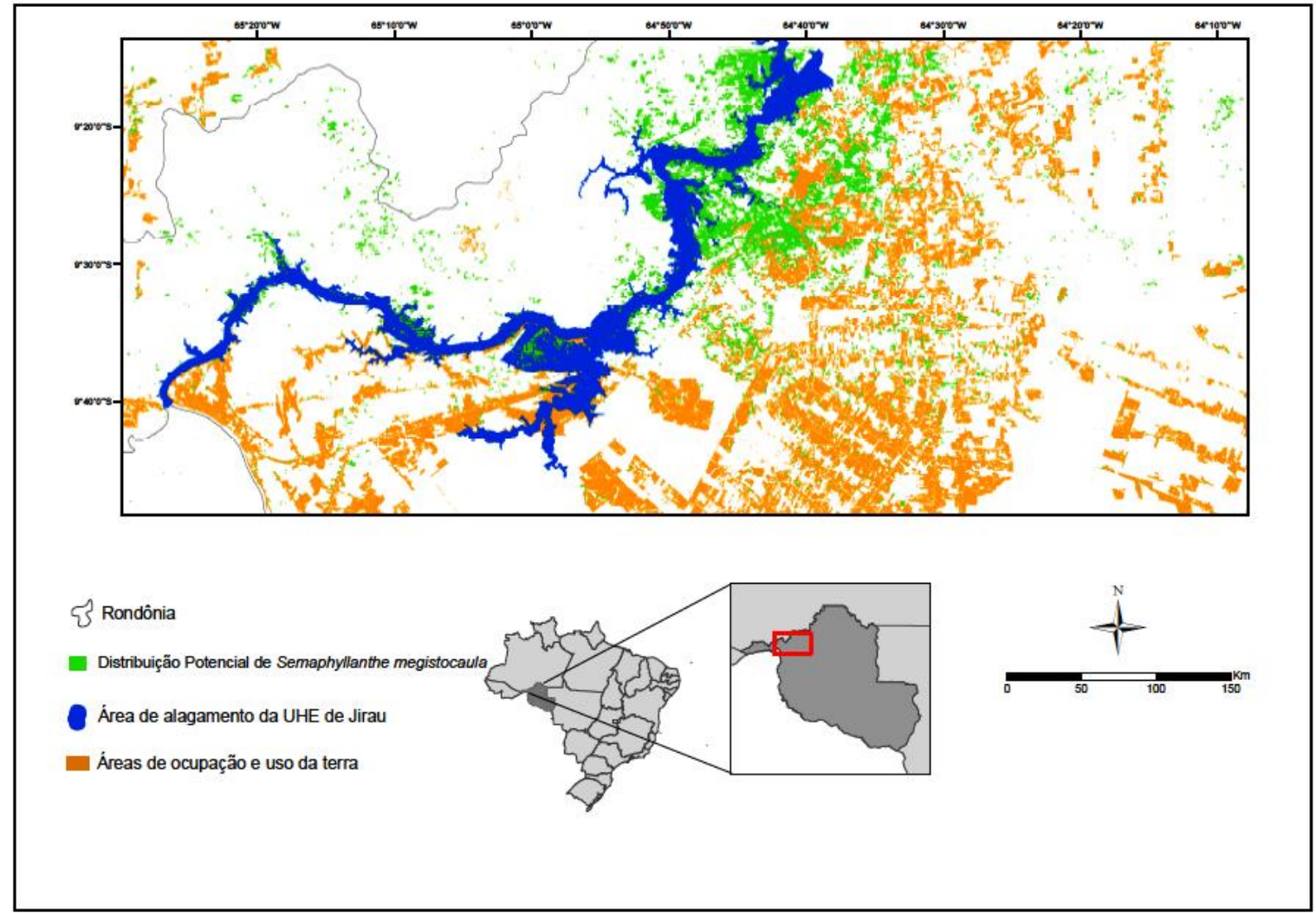

Figura 17. Área de distribuição potencial de Semaphyllanthe megistocaula (K.Krause) L.Andersson e os impactos 'alagamento da UHE de Jirau' e 'desmatamento' na bacia do alto rio Madeira, sudoeste da Amazônia brasileira, Brasil (Imagem de agosto de 2014, UTM zona 20S, DATUM: WGS 84). 


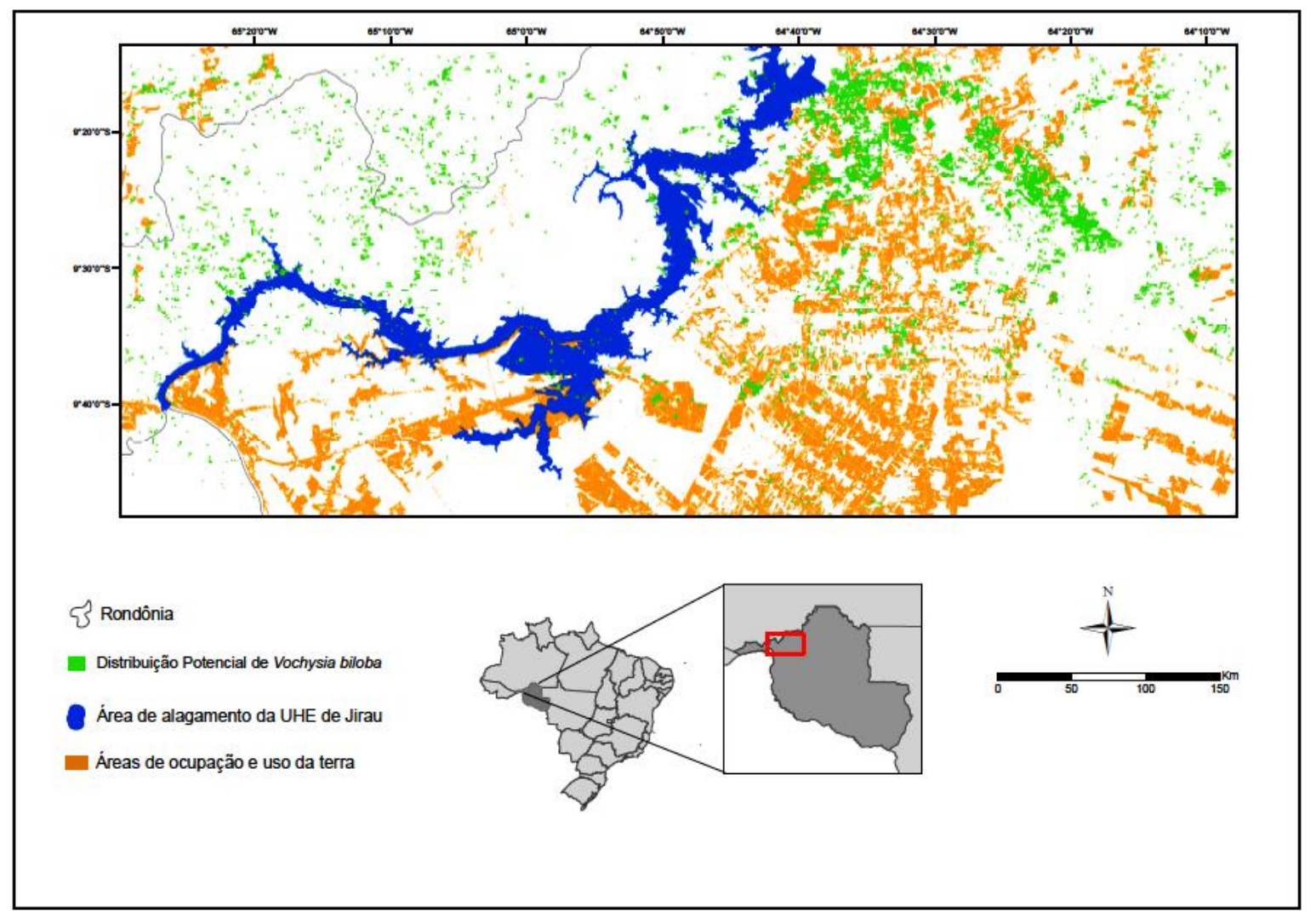

Figura 18. Área de distribuição potencial de Vochysia biloba Ducke e os impactos 'alagamento da UHE de Jirau' e 'desmatamento' na bacia do alto rio Madeira, sudoeste da Amazônia brasileira, Brasil (Imagem de agosto de 2014, UTM zona 20S, DATUM: WGS 84). 


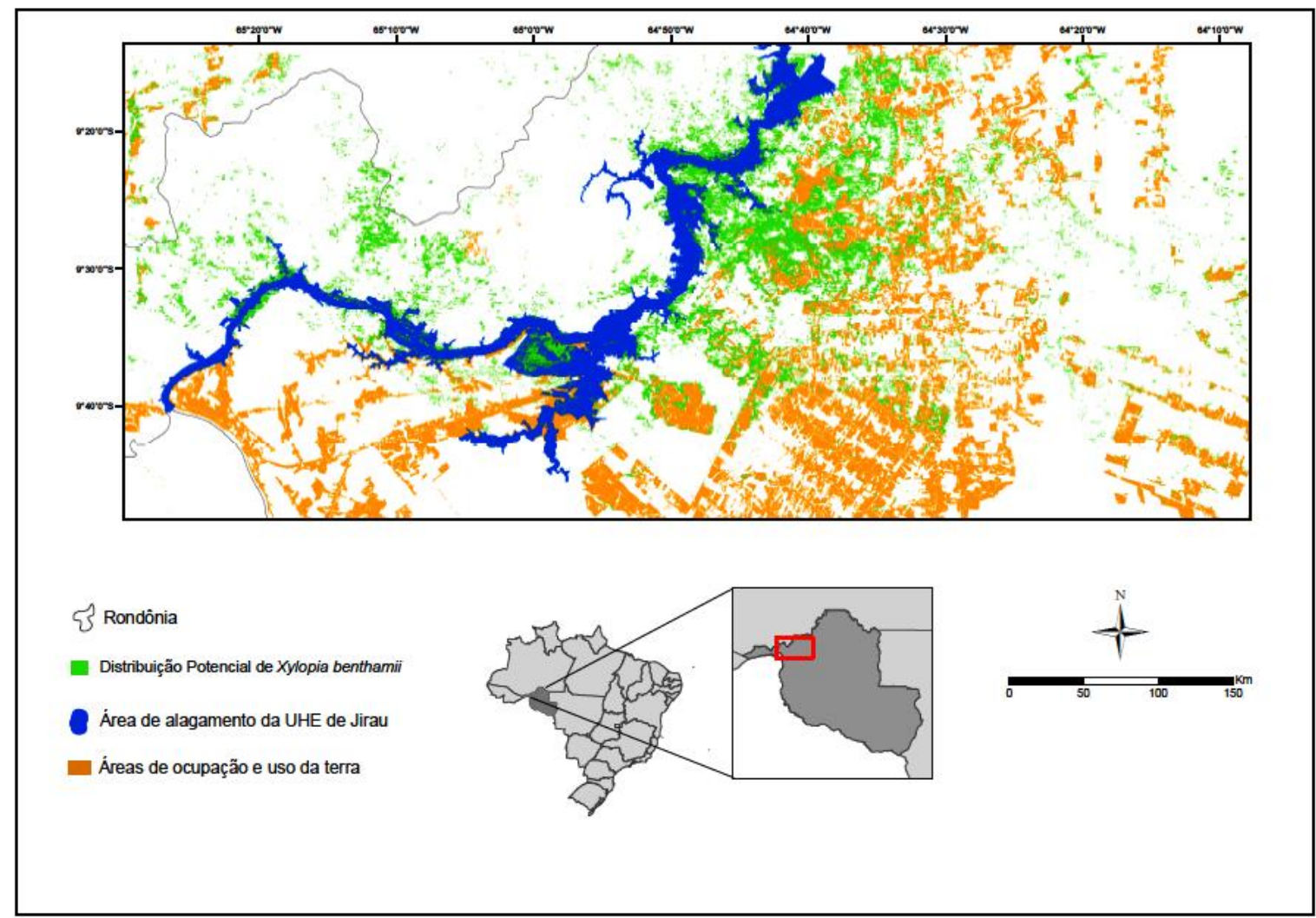

Figura 19. Área de distribuição potencial de Xylopia benthamii R.E.Fr e os impactos 'alagamento da UHE de Jirau' e 'desmatamento' na bacia do alto rio Madeira, sudoeste da Amazônia brasileira, Brasil (Imagem de agosto de 2014, UTM zona 20S, DATUM: WGS 84).

As perdas de áreas de distribuição potencial para o impacto "desmatamento" variaram de $6,7 \%$ a $34,1 \%$. As espécies com maiores porcentagens de perdas de áreas potenciais foram Moronobea coccinea Aubl. (34,1\%), Vochysia biloba Ducke (15,7\%) e Xylopia benthamii R.E.Fr. (15,4\%) (Figura 20) (Tabela 4).

O impacto 'alagamento da UHE de Jirau' variou em porcentagens de áreas de distribuição potencial perdidas entre 1,7\% e 8,2\%. A espécie Buchenavia congesta Ducke teve maior porcentagem de perda de área de distribuição potencial pelo 'alagamento' $(4,3 \%)$ do que pelo 'desmatamento' $(3,1 \%)$. Os maiores valores de perdas de áreas de distribuição potencial pelo impacto 'alagamento' foram para as espécies Semaphyllanthe megistocaula (K.Krause) L.Andersson (8,2\%) e Chrysophyllum colombianum (Aubrév.) T.D.Penn. (7,7\%). A espécie Brosimum parinarioides Ducke apresentou pouca diferença entre os dois impactos, com 6,3\% para perdas pelo 'alagamento da UHE de Jirau' e 6,7\% para perdas pelo 'desmatamento'. 
Os dois impactos somados obtiveram perdas de áreas de distribuição potencial com variação entre $7,4 \%$ e $37,3 \%$. As espécies apontadas como mais vulneráveis diante dos dois impactos foram Moronobea coccinea (37,3\%) e Xylopia benthamii (22,3\%).

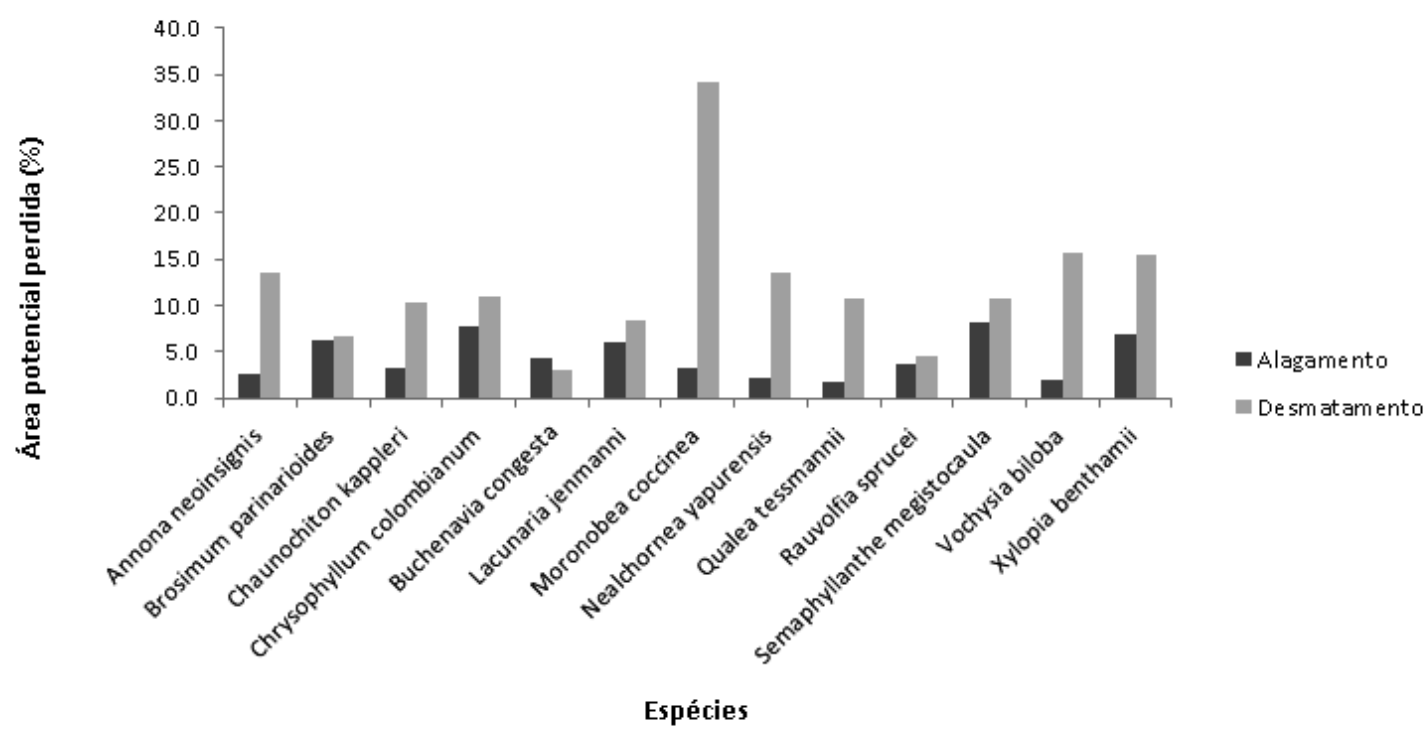

Figura 20. Áreas de distribuição potencial perdidas em porcentagem por impactos "alagamento da UHE de Jirau" e "desmatamento" para 13 espécies arbóreas localmente raras na bacia do alto rio Madeira, sudoeste da Amazônia brasileira, Brasil. 
Tabela 4. Tamanho e porcentagem das áreas de distribuição potenciais de espécies arbóreas localmente raras na bacia do alto rio Madeira, sudoeste da Amazônia brasileira, Brasil e perda dos nichos por impactos "alagamento da UHE de Jirau" e "desmatamento".

\begin{tabular}{lcccccc}
\multicolumn{1}{c}{ Espécie } & $\begin{array}{c}\text { Área total nicho } \\
(\mathbf{m} 2)\end{array}$ & Alagamento & \% & Desmatamento & $\begin{array}{c}\text { Total } \\
\%\end{array}$ \\
\hline Annona neoinsignis & 28068131,6 & 744631,8 & 2,7 & 3828786,0 & 13,6 & 16,3 \\
Brosimum parinarioides & 17574821,6 & 1110301,7 & 6,3 & 1174695,6 & 6,7 & 13,0 \\
Chaunochiton kappleri & 26535260,3 & 833944,4 & 3,1 & 2719563,7 & 10,3 & 13,4 \\
Chrysophyllum colombianum & 4007997,2 & 307629,0 & 7,7 & 442060,6 & 11,0 & 18,7 \\
Buchenavia congesta & 5596195,6 & 853466,2 & 4,3 & 1187925,9 & 3,1 & 7,4 \\
Lacunaria jenmanni & 20029007,2 & 1213338,1 & 6,1 & 1671805,6 & 8,4 & 14,4 \\
Moronobea coccinea & 5541084,5 & 179026,2 & 3,2 & 1888950,0 & 34,1 & 37,3 \\
Nealchornea yapurensis & 16241361,7 & 335138,3 & 2,1 & 2205245,0 & 13,6 & 15,6 \\
Qualea tessmannii & 37979645,0 & 658649,9 & 1,7 & 4048829,4 & 10,7 & 12,4 \\
Rauvolfia sprucei & 17691859,4 & 650014,7 & 3,7 & 811153,7 & 4,6 & 8,3 \\
Semaphyllanthe megistocaula & 14068498,7 & 1151380,6 & 8,2 & 1512455,3 & 10,8 & 18,9 \\
Vochysia biloba & 13874391,7 & 273828,4 & 2,0 & 2174682,6 & 15,7 & 17,7 \\
Xylopia benthamii & 20011274,2 & 1391932,6 & 7,0 & 3078818,9 & 15,4 & 22,3 \\
\hline
\end{tabular}




\section{DISCUSSÃO}

A contribuição de maneira complementar da pré-modelagem e da Avaliação Ecológica Rápida - AER foi imprescindível para que a modelagem de nicho ecológico final fornecesse informações confiáveis sobre as áreas de distribuição potencial das espécies. Os modelos de nicho ecológico apresentam informações biogeográficas sobre táxons pouco estudados e/ou raros, entretanto são extremamente necessários conhecimentos ecológicos complementares a esses estudos (Raxworthy et al. 2003; Pearson et al. 2007; Jiménez-Valverde et al. 2008). A partir da junção dos modelos com a AER e referências taxonômicas pode-se caracterizar o ambiente em que cada espécie estava inserida, assim como suas preferências em habitat. Desta forma, este trabalho se torna compatível com a literatura que utiliza modelagem de nicho com o respaldo de dados ecológicos das espécies, a fim de discernir com propriedade sobre a distribuição potencial destas (Guisan et al. 2006; Siqueira et al. 2008; Marcer et al. 2013). Com base nesse pressuposto, as avaliações de impactos deste trabalho, baseadas nos modelos, geraram informações importantes sobre as áreas de ocorrência potenciais das espécies arbóreas raras naquela região.

Os altos percentuais em perdas de áreas de distribuição potencial pelo 'desmatamento', atingindo 99\% das espécies raras deste estudo, indicam que este tipo de distúrbio exerce predominância na área. A intensidade destas modificações da paisagem sobre a biodiversidade da Floresta Amazônica deve ter especial atenção a espécies raras. O desflorestamento e a fragmentação da Amazônia brasileira são considerados como processos contínuos iniciados na região há mais de três décadas e com grande intensificação até os anos de 1990, devido aos incentivos governamentais em migração e exploração latifundiária (Fearnside 2005). Com isso, o acelerado desmatamento registrado na região central de Rondônia entre os anos de 1984 e 2002 tornou as pastagens a paisagem predominante no estado (Ferraz et al. 2005). Assim, apenas o impacto pelo 'desmatamento' representa forte fator de vulnerabilização para toda a área do estudo.

O impacto por 'desmatamento' teve abrangência tanto em áreas de Várzeas, com perdas de áreas de distribuição potencial para espécies como Annona neoinsignis (Annonaceae) e Nealchornea yapurensis (Euphorbiaceae), quanto em Terra Firme, como Moronobea coccinea (Clusiaceae), Vochysia biloba (Vochysiaceae) e Xylopia benthamii 
(Annonaceae). Esta abrangência do 'desmatamento' reforça a ideia de que a perda de habitat e a fragmentação da Amazônia brasileira são compostas por mosaicos diversos, com retiradas de vegetação em diferentes concentrações que podem influenciar na perda biológica de espécies em situação de vulnerabilidade (Skole \& Tucker 2007). A maioria dos impactos por desmatamento difere qualitativa e quantitativamente entre ecossistemas tropicais e depende de diversos fatores (Laurence 2009), dentre eles a existência de espécies especialistas ou com padrões de distribuição espacial singulares, semelhante ao que constatamos para as espécies raras deste estudo. Desta forma, os mosaicos oriundos do impacto por 'desmatamento' é severo por causar perdas consideráveis de espécies raras, vulneráveis localmente por terem suas populações ameaçadas em ambientes diversos na área do estudo.

O impacto pelo 'alagamento da UHE de Jirau' também teve porcentagens de perdas de áreas potenciais consideráveis tanto para espécies características de Florestas de Várzeas, como Brosimum parinarioides (Moraceae) e Lacunaria jenmanni (Quiinaceae), quanto para aquelas ocorrentes em Florestas de Terra Firme, como Semaphyllanthe megistocaula (Rubiaceae), Chrysophyllum colombianum (Sapotaceae) e Xylopia benthamii. Estes dois ambientes se diferem em gradientes com alta dissimilaridade nos padrões florísticos devido a fatores como topografia, textura, fertilidade do solo (Gama et al. 2005; Haugaasen \& Peres 2006) e condições adaptativas, como no caso das Florestas de Várzeas que possuem espécies especializadas a inundações sazonais e condições edáficas anaeróbicas (Wittmann et al. 2012). As grandes porcentagens de perdas de áreas de distribuição potencial pelo impacto do 'alagamento' para espécies encontradas em Florestas de Terra Firme, como Semaphyllanthe megistocaula e Chrysophyllum colombianum, chamam a atenção para a alta abrangência do impacto ao longo do gradiente vegetacional. Esta abrangência ao longo das formações florestais reforça a vulnerabilidade da área do estudo quanto a impactos irreversíveis, como os causados por alagamentos, com grandes perdas biológicas.

O impacto pelo 'alagamento da UHE de Jirau' destacou-se para espécies com ocorrência em Florestas de Várzea, como Buchenavia congesta (Combretaceae). As Várzeas do rio Madeira são apontadas como mais frágeis aos impactos da hidrelétrica de Jirau por possuírem terrenos mais planos na margem direita, vulneráveis à inundação artificial (Moser et al. 2014). Ainda que espécies como Buchenavia congesta, que compõem estas formações, sejam resistentes a inundações sazonais, os alagamentos de 
hidrelétricas geram intolerância ao tempo de permanência e a quantidade de água que ultrapassam os níveis naturais (Muller 1995; Ferreira \& Stohlgren 1999). Considerando que Florestas de Várzeas são zonas importantes de dispersão de propágulos (Wittmann et al. 2006) e que espécies raras possuem restrições reprodutivas e de densidade que dificultam a sua propagação (Gaston 1994; Kunin \& Gaston 1997), as perdas de distribuição potencial em áreas, como as Várzeas, que favoreceriam o estabelecimento e a dispersão dessas espécies raras são agravantes quando somadas.

O maior percentual em perdas de área de distribuição potencial pelos impactos antrópicos foi para Moronobea coccinea. Esta espécie é descrita por Ribeiro et al. (1999) como ocasional para a Amazônia brasileira e para as Guianas. Com exceção de Vochysia biloba e Buchenavia congesta as demais espécies possuem ocorrências ocasionais e frequentes em outras regiões da Amazônia (Ribeiro et al. 1999; Forzza et al. 2015). Ainda sim, estudos sobre vulnerabilidade e extinção de espécies alertam que após a fragmentação do habitat continuamente de uma espécie e sua extinção local, a perda inicial deste habitat gera posteriormente efeitos cascatas em decaimentos demográficos e estocásticos que operam sobre as populações em outras escalas (Watson et al. 2002). A fragmentação causada por impactos antrópicos, mesmo em escalas locais, pode ter impactos de grandes proporções na dinâmica de populações, especialmente para espécies com baixas densidades (Laurance et al. 1998; Andersson et al. 2000; Merrit et al. 2010; Laurance et al. 2011). Afinal, apesar da ocorrência ocasional em outras localidades da Amazônia de Moronobea coccinea e das demais espécies, a vulnerabilidade local destas pode ter repercussão para todo o cenário Amazônico.

A soma dos dois impactos apresentou grandes perdas de áreas de distribuição potencial para as espécies raras em ambientes de Florestas de Várzea e Floresta de Terra Firme complementarmente, com alta restrição das ocorrências de modo geral no local do estudo. Espécies arbóreas raras na Amazônia são as mais sensíveis aos efeitos de perturbações, sendo as primeiras a apresentarem grandes decaimentos populacionais em resposta a impactos, de forma que alguns grupos são comprometidos ao risco iminente de extinção (te Steege et al. 2015). A avaliação de impactos ambientais aponta a importância de espécies bioindicadoras que refletem algum aspecto do estado do ambiente em que se encontram (Mcgeoch 2013). Segundo o mesmo autor, estas espécies ou grupos de espécies são usadas para retratar condições ambientais e monitorar mudanças, a fim de extrair informações abióticas ou bióticas que contribuirão para tomadas de decisões de gestão e 
políticas com base científica. Desta forma, pode se considerar que as perdas de áreas de distribuição potencial das espécies raras representam bioindicadores do sinergismo de impactos antrópicos e contribuem com informações biológicas sobre a conservação do local do estudo.

Em síntese, podemos afirmar que os impactos pelo 'desmatamento' e pelo 'alagamento da UHE de Jirau', juntos, são adversos e severos à distribuição potencial de espécies localmente raras, com grande magnitude e alta significância, o que representa vulnerabilidade para toda a área do estudo. Alguns trabalhos apontam que a severidade dos danos oriundos da construção de barragens de hidrelétricas, em âmbito ambiental e social, muitas vezes é impossível de ser mitigada, por serem processos contínuos de influência direta e indireta em toda escala de paisagem (Fearnside 2001; Fearnside 2006; Finer \& Jenkin 2012). Apesar de considerarmos o 'desmatamento' separadamente do 'alagamento' é evidente que ambos são interligados e que a retirada de vegetação por estradas, atividades agropecuárias e o processo de urbanização sejam aumentados pela usina hidrelétrica de Jirau.

Esse trabalho representa um único cenário local sob ameaça em perdas de biodiversidade da Amazônia brasileira, entretanto os mesmos impactos antrópicos avaliados nesse estudo são recorrentes em toda a paisagem do bioma (Ferraz et al. 2005; Laurance et al. 2011). As informações aqui obtidas com espécies raras como bioindicadores ambientais são extremamente importantes na avaliação de impactos antrópicos para este bioma e para a conservação da natureza. 


\section{CONCLUSÃO}

O impacto de distúrbios antrópicos oriundos da usina hidrelétrica de Jiraus e de desmatamentos por ocupação e uso da terra causou perdas expressivas nas áreas de distribuição potencial de espécies arbóreas raras no alto rio Madeira, sudoeste da Amazônia brasileira. A perda e a fragmentação de habitat pelo 'desmatamento' e 'alagamento da UHE de Jirau' atingiram aleatoriamente espécies ocorrentes em diversos ambientes, como Florestas de Várzeas e Florestas Terra Firme, o que restringiu a distribuição destas espécies raras tanto na área de influência direta e indireta do empreendimento.

Os impactos pelo 'alagamento da UHE de Jirau' e 'desmatamento' são complementares e severos sobre as populações de espécies raras. Estas populações raras e naturalmente sensíveis a impactos ambientais se apresentaram como potenciais bioindicadores para inferir sobre a vulnerabilidade da área sob pressões antrópicas. 


\section{CONSIDERAÇÕES FINAIS}

A pré-modelagem contribuiu de forma eficaz no direcionamento das coletas de dados adicionais de ocorrência das espécies selecionadas. Assim como verificado em outros estudos com populações raras (Siqueira et al. 2008), o algoritmo Environmental Distance proporcionou aumento considerável no número de novos registros e na caracterização dos ambientes de ocorrência das espécies.

Apesar dos índices de vegetação (NDVI) utilizados na composição deste trabalho possivelmente subestimarem a distribuição potencial das espécies por não considerarem as áreas florestais mais antigas, as estatísticas dos modelos gerados junto a conhecimentos prévios da área apontaram respostas sobre a distribuição potencial das espécies arbóreas raras deste estudo.

As informações geradas nesse estudo com espécies arbóreas raras caracterizam os distúrbios antrópicos na Amazônia e são de grande importância para a avaliação de impactos ambientais. A partir dessas avaliações com modelagem de nicho de bioindicadores é possível inferir estratégias de manutenção e conservação de ecossistemas vulneráveis. 


\section{REFERÊNCIAS BIBLIOGRÁFICAS}

ALLOUCHE, O.; TSOAR, A.; KADMON, R. Assessing the accuracy of species distribution models: prevalence, kappa and the true skill statistic (TSS). Journal of Applied Ecology, v.43, p. 1223-1232, 2006.

ANDERSON, R. P.; PETERSON, A. T.; GÓMEZ-LAVERDE, M. Using niche-based GIS modeling to test geographic predictions of competitive exclusion and competitiverelease in South American pocket mice. Oikos,v.98, p. 3-16, 2002.

ANDERSSON, E.; NILSSON, C.; JOHANSSON, M. E. Effects of river fragmentation on plant dispersal and riparian flora. Regulated Rivers: Research \& Management, v. 16, n. 1, p. 83-89, 2000.

ANDERSON, R.P.; LEW, D.; PETERSON, A.T. Evaluating predictive models of species' distributions:criteria for selecting optimal models. Ecological Modelling, v. 162, p. 211$232,2003$.

ARAÚJO, M.B. et al. Downscaling European species atlas distributions to a finer resolution: Implications for conservation planning. Global Ecology and Biogeography, v. 14, n. 1, p. 17-30, 2005.

ARAÚJO, M.B.; GUISAN, A. Five (or so) challenges for speciesdistribution modeling. Journal of Biogeography, v.33, 1677-1688, 2006.

AUSTIN, M.P.; VAN NIEL, K.P. Improving species distribution models for climate change studies: Variable selection and scale. Journal of Biogeography, v. 38, n. 1, p. 1-8, 2010 .

BENÍTEZ-MALVIDO, J.; MARTÍNEZ-RAMOS, M. Impact of Forest Fragmentation on Understory Plant Species Richness in Amazonia. Conservation Biology, v. 17, n. 2, p. 389-400, 2003.

BOOTH, J. E. et al. The value of species rarity in biodiversity recreation: A birdwatching example. BiologicalConservation, v. 144, n. 11, p. 2728-2732, 2011.

BRASIL. Decreto $\mathbf{n}^{\mathbf{0}}$ 11612, de 5 de junho de 2008. Dispõe sobre a criação do Parque Nacional Mapinguari, nos Municípios de Canutama e Lábrea, no Estado do Amazonas, e dá outras providências. Disponível em: http://www.planalto.gov.br/ccivil_03/_ato20072010/2008/Dnn/Dnn11612.htm Acesso em: 01 de jan de 2016.

BRASIL. Lei $\mathbf{n}^{\mathbf{0}}$ 12.678, de 25 de junho de 2012. Dispõe sobre alterações nos limites dos Parques Nacionais da Amazônia, dos Campos Amazônicos e Mapinguari, das Florestas Nacionais de Itaituba I, Itaituba II e do Crepori e da Área de Proteção Ambiental do Tapajós; altera a Lei no 12.249, de 11 de junho de 2010; e dá outras providências. Disponível em: http://www.planalto.gov.br/ccivil_03/_Ato20112014/2012/Lei/L12678.htm Acesso em: 05 de nov de 2015. 
BROADBENT, E.N.; ASNER, G.P.; KELLER, M.; KNAPP, D.E.; OLIVEIRA, P.J.C.; SILVA, J.N. Forest fragmentation and edge effects from deforestationand selective logging in the Brazilian Amazon. Biological Conservation, v. 141, p. 1745 - 1757, 2008.

BROENNIMANN, O. et al. Rarity types among plant species with high conservation priority in Switzerland. Botanica Helvetica, v. 115, n. 2, p. 95-108, 2005.

BROWN, J. H. On the Relationship between Abundance and Distribution of Species. The American Naturalist, v. 124, n. 2, p. 255, 1984.

CADOTTE, M. W.; LOVETT-DOUST, J. Ecological and taxonomic differences between rare and common plants southwestern Ontario. Ecoscience, v.9, n.3, 397-406, 2002.

CHUYONG, G. B. et al. Habitat specificity and diversity of tree species in an African wet tropical forest. Plan Ecol, p. 1363-1374, 2011.

CLARK, D. B.; CLARK, D. A.; READ, J. M. Edaphic variation and the mesoscale distribution of tree species in a neotropical rain forest. Journal of Ecology, v. 86, n. 1, p. 101-112, 1998.

COCHRANE, T.T.; COCHRANE, T.A. Amazon Forest and Savanna Lands: A guide to the climates, vegetation, landscapes, and soils of Central Tropical South America. Create Space Independent Publishing Platform, Seattle, WA. 2010.

COFRE, H.L.; BÖHNING-GAESE, K.; MARQUET, P.A. Rarity in Chilean forest birds: which ecological and life-history traits matter? Universidad Nacional Andrés Bello. Santiago, Chile, 2007.

COURCHAMP, F. et al. Rarity Value and Species Extinction: The Anthropogenic Allee Effect. PLoS Biology, v. 4, n. 12, p. e415, 2006.

CUNHA, D. D. E. A.; FERREIRA, L. V. Impacts of the Belo Monte hydroelectric dam construction on pioneer vegetation formations along the Xingu River, Pará State, Brazil. Brazilian Journal of Botany, v. 35, n. 2, p. 159-167, 2012.

CUNNINGHAM, R. B.; LINDENMAYER, D. B. Modeling count data of rare species: Some statistical issues. Ecology, v. 86, n. 5, p. 1135-1142, 2005.

DARWIN, C.A Origem das Espécies, no meio da seleção natural ou a luta pela existência na natureza. v.1, 1859.

DORMANN, C.F. Promising the future? Global change projections of species distributions. Basic andAppliedEcology, v. 8 , p. 387-397, 2007.

DE MARCO Jr., P.; SIQUEIRA, M.F. Como determinar a distribuição potencial de espécies sob uma abordagem conservacionista? Megadiversidade, v. 5 n.1-2, 2009.

ELITH, J. et al. Novel methods improve prediction of species' distributions from occurrence data. Ecography, v. 29, p. 129-151, 2006.

EMBRAPA - Empresa Brasileira de Pesquisa Agropecuária. Manual de Métodos de Análise de Solo. Serviço Nacional de Levantamento e Conservação de Solos. Rio de Janeiro.1979. 
ENGLER, R.; GUISAN, A.; RECHSTEINER, L. An improved approach for predicting the distribution of rare and endangered species from occurrence and pseudo-absence data. Journal of Applied Ecology, v. 41, p. 263-274, 2004.

FATTORINI, S. Relations between species rarity, vulnerability, and range contraction for a beetle group in a densely populated region in the Mediterranean biodiversity hotspot. Conservation biology : the journal of the Society for Conservation Biology, v. 28, n. 1, p. 169-76, 2014.

FEARNSIDE, P. M. Environmental Impacts of Brazil's Tucuruí Dam: Unlearned Lessons for Hydroelectric Development in Amazonia. Environmental Management, v. 27, n. 3, p. 377-396, 2001.

FEARNSIDE, P. M. Desmatamento na Amazônia: dinâmica, impactos e controle. Acta Amazonica, v. 36, n. 3, p. 395-400, 2006.

FERRAZ, S. F. de B. et al. Landscape dynamics of Amazonian deforestation between 1984 and 2002 in central Rondônia, Brazil: assessment and future scenarios. Forest Ecology and Management, v. 204, n. 1, p. 69-85, 2005.

FERREIRA, L. V.; CUNHA, D.A.; LEAL, D.C.; CHAVES, P.P. Impacts of the hydroelectric dams in the endemic plant communities of floodplains of the Tapajós, Xingu and Tocantins Rivers in Eastern Amazonian. Acad. Bras. Ciênc, v. 85, p. 241-251, 2013.

FERREIRA, J. et al. Brazil's environmental leadership at risk. Science, v.346, 2014.

FICETOLA, G.F.; BONARDI, A.; MÜCHER, C.A.; GILISSEN, N.L.M.; PADOASCHIOPPA, E. How many predictors in species distribution models at the landscape scale? Land use versus LiDAR-derived canopy height. International Journal of Geographical Information Science, 2014.

FIEDLER, P. L. Life history and population dynamics of rare and common Mariposa Lilies (CalochortusPursh: Liliaceae). Journal of Ecology, v. 75, n. 4, p. 977-995, 1987.

FIELDING, A. H.; BELL, J. F. A review of methods for the assessment of prediction errors in conservation presence / absence models. Environmental Conservation, v. 24, n. 1, p. 38-49, 1997.

FIGUEIREDO, F. O. G. et al. Validating forest types based on geological and land-form features in central Amazonia. Journal of Vegetation Science, v. 25, n. 1, p. 198-212, 2014.

FINER, M.; JENKINS, C.N. Proliferation of hydroelectric dams in the Andean Amazon and implications for Andes-Amazon connectivity. PLoSONE, v. 7, n. 4, p. e35126, 2012.

FLATHER, C. H.; SIEG, C. H. Species rarity: Definition, Causes, and Classification. Conservation of rare or little-know species, p. 40-66, 2001.

FOLEY, J.A. et al. Amazonia revealed: forest degradation and loss of ecosystem goods and services in the Amazon Basin. Front Ecol. Environ, v. 5, p. 25-32, 2007.

FORZZA, R.C. et al. Lista de Espécies da Flora do Brasil. Jardim Botânico do Rio de Janeiro. 2014. Disponível em: <http://floradobrasil.jbrj.gov.br/2010/> Acesso em: 30 de novembrode 2015. 
FRANKLIN, J. Mapping Species Distributions: Spatial Inference and Prediction. Ecology, Biodiversity and Conservation. Cambrigdge. 2009.

FREEMAN, E.A.; MOISEN, G.G. A comparison of the performance of threshold criteria for binary classification in terms of predicted prevalence and kappa. Ecological Modelling, v. 217, n. 1-2, p. 48-58, 2008.

GAMA, J.R.V.; SOUZA, A.L.; MARTINS, S.V.; SOUZA, D.R. Comparação entre florestas de Várzea e de Terra Firme do estado do Pará. R. Árvore, v.29, n.4, p.607-616, 2005 .

GASTON, K.J. Rarity. Chapman \& Hall. 1994.

GASTON, K. J. Rarity as double jeopardy. Nature, v. 394, p. 229-230, 1998.

GASTON, K. J. The importance of being rare. Nature, v. 487, n. 7405, p. 46-47, 2012.

GIANNINI, T.C. Distribuição geográfica de abelhas e plantas associadas através de modelagem computacional. Instituto de Biociências da Universidade de São Paulo. Departamento de Ecologia. São Paulo, 2011.

GIULIETTI, A.M. et al.Plantas raras do Brasil. Conservação Internacional. Belo Horizonte, MG, 2009.

GIOVANELLI, J. G. R. et al. Modelagem do nicho ecológico de Phyllomedusaayeaye (Anura: Hylidae): previsão de novas áreas de ocorrência para uma espécie rara. Neotropical Biology and Conservation, v. 3, n. 2, p. 59-65, 2008.

GOOVAERTS, P. Geostatistics in soil science: State-of-the-art and perspectives. Geoderma, v. 89, n. 1-2, p. 1-45, 1999.

GRAF, R.F.; BOLLMANN, K.;SUTER, W.; BUGMANN, H. The importance of spatial scale in habitat models: capercaillie in the Swiss Alps. Landscape Ecology, v.20, p. 703$717,2005$.

GUISAN, A.; ZIMMERMMAN, N.E. Predictive habitat distribution models in ecology. Ecological Modelling, v.135, p. 147-186, 2000.

GUARINO, E. D. S. G.; BARBOSA, A. M.; WAECHTER, J. L. Occurrence and abundance models of threatened plant species: Applications to mitigate the impact of hydroelectric power dams. Ecological Modelling, v. 230, p. 22-33, 2012.

GUISAN, A.; BROENNIMANN, O.; ENGLER, R.; VUST, M.; YOCCOZ, N.G.; LEHMANN, A.; ZIMMERMANN, N.E. Using Niche-Based Models to Improve the Sampling of Rare Species. Conservation Biology, v.20, n. 2, p. 501-511, 2005.

GUISAN, A.; THUILLER, W. Predicting species distribution: offering more than simple habitat models. Ecology Letters, v.8, p. 993-1009, 2005.

HANLEY, J. A; MCNEIL, B. J. The meaning and use of the area under a receiver operating characteristic (ROC) curve. Radiology, v. 143, n. 1, p. 29-36, 1982.

HANSKI, I. Distributional ecology of anthropochorous plants in villages surrounded by forestAnn. Bot. Fennici, 1982. 
HARNIK, P. G.; SIMPSON, C.; PAYNE, J. L. Long-term differences in extinction risk among the seven forms of rarity. Proceedings of the Royal Society B: Biological Sciences, v. 279, n. 1749, p. 4969-4976, 2012.

HARRISON, S. et al. Favorable environments and the persistence of naturally rare species. Conservation Letters, v. 1, n. 2, p. 65-74, 2008.

HARTLEY, S.; KUNIN, W. E. Scale Dependency of Rarity, Extinction Risk, and Conservation Priority. Conservation Biology, v. 17, n. 6, p. 1559-1570, 2003.

HAUGAASEN, T.; PERES, C. A. Floristic, edaphic and structural characteristics of flooded and unflooded forests in the lower Rio Purús region of central Amazonia, Brazil. Acta Amazonica, v. 36, n. 1, p. 25-36, 2006.

HE, F.; CONDIT, R. The distribution of species: occupancy, scale, and rarity. Scaling Biodiversity, p. 32-50, 2007.

HENLE, K.; DAVIES, K.F.; KLEYER, M.; MARGULES, C.; SETTELE, J. Predictors of species sensitivity to fragmentation. Biodiversity and Conservation, v.13, p.207-251, 2004.

HIGGINS, M. A. et al. Geological control of floristic composition in Amazonian forests. Journal of Biogeography, v. 38, n. 11, p. 2136-2149, 2011

HIJMANS, R. J.; GRAHAM, C. H. The ability of climate envelope models to predict the effect of climate change on species distributions. Global Change Biology, v.12, p. 22722281, 2006.

HONORIO CORONADO, E. N. et al. Multi-Scale Comparisons of Tree Composition in Amazonian Terra FirmeForests .Biogeosciences, v. 6, n. 11, p. 2719-2731, 2009.

HOPKINS, M. J. G. Modelling the known and unknown plant biodiversity of the Amazon Basin. Journal of Biogeography, v. 34, n. 8, p. 1400-1411, 2007.

HUBBELL S. P. The Unified Neutral Theory of Biodiversity and Biogeography. Princeton University Press, p. 392, 2011.

HUBBELL, S.P.; HE, F.; CONDIT, R.; BORDA-DE-ÁGUA, L.; KELLNER, J.; TER STEEGE, H. How many tree species are there in the Amazon and how many of them will go extinct? PNAS, v. 105, p. 11498-11504, 2008.

HUBBELL, S. P. Tropical rain forest conservation and the twin challenges of diversity and rarity. EcologyandEvolution, p. n/a-n/a, 2013.

HUSTON, M.A. Introductory Essay: Critical issues for improving predictions. Predicting species occurrences. Island Press. 2002.

HUTCHINSON, G.E. Concluding remarks. Cold Spring Harbour Symposium on Quantitative Biology, v. 22, p. 415-427, 1957.

IBGE. Manual técnico da vegetação brasileira. Ministério do Planejamento, Orçamento e Gestão. Instituto Brasileiro de Geografia e Estatística - IBGE. Rio de Janeiro. 2012.

INMET. Instituto Nacional de Metereologia. Disponível em: <http://www.inmet.gov.br/html/clima/mapas/> Acesso em: 30 de nov. 2015. 
JANSSON, R.; NILSSON, C.; RENÖFÄLT, B. Fragmentation of riparian floras in rivers with multiple dams. Ecology, v.81, n.4, pp. 899-903, 2000.

JIMÉNEZ-VALVERDE, A.; LOBO, J.M. \& HORTAL, J. Not as good as they seem: the importance of concepts in species distribution modeling. Diversity and Distributions, v.14, p. 885-890, 2008.

KUNIN, W.E.; GASTON, K.J. The biology of rarity: Patterns, causes and consequences. Trends in ecology \& evolution (Personal edition), v. 8, n. 8, p. 298-301, 1993.

KUNIN, W.E. GASTON, K.J. The Biology of Rarity. Champman\& Hall. London, 1997.

KUNIN, W.E. Extrapolating Species Abundance Across Spatial Scales. Science, v. 281, n. 5382, p. 1513-1515, 1998.

LAURANCE, W.F.; ALBERNAZ, A.K.M. Predictors of deforestation in the Brazilian Amazon. Journal of Biogeography, v. 29, p. 737-748, 2002.

LAURANCE, W.F.; GOOSEM, M.; LAURANCE, S.G.W. Impacts of roads and linear clearings on tropical forests. Trends in Ecology \& Evolution, v. 24, n. 12, p. 659-669, 2009.

LAURANCE, W.F. et al. The fate of Amazonian forest fragments: A 32-year investigation. Biological Conservation, v. 144, n. 1, p. 56-67, 2011.

LAVERGNE, S.; MOLINA, J.; DEBUSSCHE, M. Fingerprints of environmental change on the rare mediterranean flora: A 115-year study. Global Change Biology, v. 12, n. 8, p. 1466-1478, 2006.

LENNON, J.J. et al. Contribution of rarity and commonness to patterns of species richness. Ecology Letters, v. 7, n. 2, p. 81-87, 2003.

LINDENMAYER, D.B. et al. How to make a common species rare: A case against conservation complacency. Biological Conservation, v. 144, n. 5, p. 1663-1672, 2011.

LYONS, K. G.; SCHWARTZ, M. W. Rare species loss alters ecosystem function invasion resistance. Ecology Letters, v. 4, p. 358-365, 2001.

LYONS, K.G. et al. Rare Species and Ecosystem Functioning. Conservation Biology, v. 19, n. 4, p. 1019-1024, 2005.

MACPHERSON, J.M.; JETZ, W. Effects of species' ecology on the accuracy of distribution models. Ecography, v. 30, p. 135-151, 2007.

MAGNUSSON, W. E. et al. RAPELD: a modification of the Gentry method for biodiversity surveys in long-term ecological research sites. Biota Neotropica, v. 5, p. 21 26, 2005.

MANEL, S.; CERI WILLIAMS, H.; ORMEROD, S.J. Evaluating presence-absence models in ecology: The need to account for prevalence. Journal of Applied Ecology, v. 38, n. 5, p. 921-931, 2001.

MARCER, A.; SÁEZ, L.; MOLOWNY-HORAS, R.; PONS, X.; PINO, J. Using species distribution modelling to disentangle realised versus potential distributions for rare species conservation. Biological Conservation, v. 166, p.221-230, 2013. 
MARCOT, B. G.; SIEG, C. H. System-level strategies for conserving rare or little-known species. Conservation of Rare or Little-known Species: biological, social, and economic considerations, p. 165-186, 2007.

MARKHAM, J. Rare species occupy uncommon niches. Scientific Reports, v. 4, p. 63$65,2014$.

MARTINELLI, G.; MESSINA, T.; FILHO, L. DOS S. Red Book of the Flora of Brazil Rare Plants of the Cerrado, p. 320, 2014.

MCALLISTER, D.E. et al. Biodiversity Impacts of Large Dams. International Union for Conservation of Nature and Natural Resources and the United Nations Environmental Programme, n. 1, p. 63, 2001.

MCGEOCH, M. A. Bioindicators. Encyclopedia of Environmetrics, v. 1, 2013.

MERRITT, D.M.; NILSSON, C.; JANSSON, R. diversity and turnover of and river Consequences fragmentation propagule dispersal for riparian and turnover plant community diversity. Ecological Monographs, v. 80, n. 4, p. 609-626, 2014.

MOBOT. Missouri Botanical Garden. Disponível em: <http://www.tropicos.org> Acesso em: 30 de nov. 2015.

MOSER, P. Vegetação arbórea e sua relação com fatores ambientais e espaciais em florestas de terra firme no noroeste de Rondônia, Brasil. Dissertação de Mestrado. Publicação PPGEFL. DM - 226/ 2013, Programa de Pós-Graduação em Ciências Florestais, Universidade de Brasília - UnB,p.119, Brasília, DF, 2013.

MOSER, P. et al. Tree Species Distribution along Environmental Gradients in an Area Affected by a Hydroelectric Dam in Southern Amazonia. Biotropica, v. 46, n. 3, p. 367376, 2014.

MOUILLOT, D. et al. Rare Species Support Vulnerable Functions in High-Diversity Ecosystems. PLoS Biology, v. 11, n. 5, p. e1001569, 2013.

MÜLLER, N. River dynamics and floodplain vegetation and theiralterations due to human impact. Large Rivers, v. 9, n.3-4, p. 477-512, 1995.

MUÑOZ, M.E.S.; GIOVANNI, R.; SIQUEIRA, M.F.; SUTTON, T.; BREWER, P.; PEREIRA, R.S.; CANHOS, D.A.L.; CANHOS, V.P. OpenModeller: a generic approach to species' potential distribution modelling. GeoInformatica. 2009.

NAEEM, S.; WRIGHT, J. P. Disentangling biodoversity effects on ecosystem functioning: deriving solutions to a seemingly insormountable problem. Ecology Letters, v. 6, p. 567$579,2003$.

PEARSON, R. G.; DAWSON, T. P. Predicting the impacts of climate change on the distribution of species: are bioclimate envelope models useful? Global Ecology \& Biogeography, v. 12, p. 361-371, 2003. 
PEARSON, R.G.; THUILLER, W.; ARAÚJO, M.B.; MARTINEZ-MEYER, E.; BROTONS, L.; MCCLEAN, C.; MILES, L.; SEGURADO, P.; DAWSON, T.P.; LEES, D.C. Journal of Biogeography, v.33, p. 1704-1711, 2007.

PERIGOLO, N.A. Caracterização dos tipos vegetacionais do médio rio Madeira, Rondônia. Dissertação de mestrado. Departamento de Botânica do Instituto de Ciências Biológicas da Universidade de Brasília - UNB. Brasília, DF, 2014.

PETERSON, A.T.; COHOON, K.P. Sensitivity of distributional prediction algorithms to geographic data completeness. Ecological Modelling, v. 117, n. 1, p. 159-164, 1999.

PETERSON, A.T. Predicting species geographic distributions based on ecological niche modeling. The Condor, v. 103, p. 599-605, 2001.

PETERSON, A.T.; KLUZA, D.A. Ecological Niche Modeling as a New Paradigm for Large-Scale Investigations of Diversity and Distribution of Birds. USDA Forest Service General Technical Report, v. PSW-GTR, n. 191, p. 1201-1204, 2005.

PETERSON, A.T.; PAPEŞ, M.; EATON, M. Transferability and model evaluation in ecological niche modeling: A comparison of GARP and Maxent. Ecography, v. 30, n. 4, p. 550-560, 2007.

PETERSON, A. T. et al. Ecological niches and geographic distributions. Princeton University Press, 2011.

PHILLIPS, O. L. et al. Habitat association among Amazonian tree species: A landscapescale approach. Journal of Ecology, v. 91, n. 5, p. 757-775, 2003.

PHILLIPS, S.; ANDERSON, R.; SCHAPIRE, R. Maximum entropy modeling of species geographic distributions. Ecological Modelling, v. 190, n. 3-4, p. 231-259, 2006.

PITMAN, N.C.A. et al. Tree species distribution in an upper Amazonian forest. Ecology. Ecology, v. 80, n. 8, p. 2651-2661, 1999.

PITMAN, N.C.A.; TERBORGH, J.W.; SILMAN, M.R.; NUNEZ, P.V.; NEILL, D.A.; CERÓN, C.E.; PALACIOS, W.A.; AULESTIA, M. Dominance and distribution of tree species inupper Amazonianterra firme forests. Ecology, v.82, n.8, p. 2101-2117, 2001.

POFF, N. L. et al. The Natural Flow Regime: A paradigm for river conservation and restoration N. BioScience, v. 47, n. 11, p. 769-784, 1997.

PRATES-CLARK, C.D.C.; SAATCHI, S.S.; AGOSTI, D. Predicting geographical distribution models of high-value timber trees in the Amazon Basin using remotely sensed data. Ecological Modelling, v. 211, n. 3-4, p. 309-323, 2008.

PRESTON, F.W. The commonness, and rarity, of species. Ecology, v. 29, n. 3, p. 254283, 1948.

PRESTON, F.W. The Canonical Distribution of communness and rarity: Part I. Ecology, v. 43, n. 2, pp. 185-215, 1962.

R DEVELOPMENT CORE TEAM. R: A language and environment for statistical computing. R Foundation for Statistical Computing, Vienna, Austria. 2015. 
RABINOWITZ, D. Seven forms of rarity. The biological aspects of rare plant conservation, v. -, p. 205-217, 1981.

RABINOWITZ, D.;CAIRNS, S.; DILLON, T. Seven forms of rarityand their frequency in the flora of the BritishIsles. Conservation Biology: The Science of Scarcity and Diversity, Soulé, M.E., (ed), Sinauer Associates, pp. 182-204, 1986.

RABUS, B. et al. The shuttle radar topography mission - a new class of digital elevation models acquired by spaceborne radar. ISPRS Journal of Photogrammetry and Remote Sensing, v. 57, n. 4, p. 241-262, 2003.

RAMÍREZ-VILLEGAS, J. et al. A gap analysis methodology for collecting crop genepools: A case study with Phaseolus beans. PLoS ONE, v. 5, n. 10, p. e13497, 2010.

RAXWORTHY, C.J. et al. Predicting distributions of known and unknown reptile species in Madagascar. Nature, v. 426, n. 6968, p. 837-841, 2003.

RODRIGUES, A.S.L.; GASTON, K.J. Rarity and Conservation Planning across Geopolitical Units. Conservation Biology, v. 16, n. 3, p. 674-682, 2002.

RIBEIRO, J.E.L.S. et al. Flora da Reserva Ducke: Guia de identificação das plantas vasculares de uma floresta de terra-firme na Amazônia Central. Instituto Nacional de Pesquisas da Amazônia/DFID, Manaus, Amazonas, 816 p. 1999.

RICKLEFS, R.E. Rarity and diversity in Amazonian forest trees. TREE, v.15, n.3, 2000.

RIZZOTTO G.J.; QUADROS M.L.E.S.; BAHIA R.B.C.; DALL'IGNA L.G.; CORDEIRO A.V. Folha SC.20-Porto Velho. In: Carta Geológica do Brasil ao Milionésimo, Sistema de Informações Geográficas. (eds.SCHOBBENHAUS C.; GONÇALVES J.H.; SANTOS J.O.S.; ABRAM M.B.; LEÃO NETO R.; MATOS G.M.M.; VIDOTTI R.M.; RAMOS M.A.B.; JESUS J.D.A.d.). Programa Geologia do Brasil. CPRM, Brasília. CD-ROM. 2004.

RUOKOLAINEN, K. et al. Are floristic and edaphic patterns in Amazonian rain forests congruent for trees, pteridophytes and Melastomataceae? Journal of Tropical Ecology, v. 23, p. 13-25, 2007.

SAATCHI, S. et al. Modeling distribution of Amazonian tree species and diversity using remote sensing measurements. Remote Sensing of Environment, v. 112, n. 5, p. 20002017, 2008.

SAETERSDAL, M. Rarity and species/area relationships of vascular plants in deciduous woods, western Norway--Applications to nature reserve selection. Ecography, v. 17, n. 1, p. 23-38, 1994.

SAYRE, R.; ROCA, E.; SEDAGHATKISH, G.; YOUNG, B.; KEEL, S.; ROCA, R.; SHEPPARD, S. Natureza em foco: avaliação ecológica rápida. Island Press, Washington, DC, 2003.

SCHEMSKE, D.W. et al. Evaluating approahes to the conservation of rare and endangered plants. Ecology, v. 75, n. 3, p. 584-606, 1994.

SCHOENER, T.W. The geographical distribution of rarity. Oecologia, v. 74, n. 2, p. 161173, 1987. 
SCULL, P.; FRANKLIN, J.; CHADWICK, O. A. The application of classification tree analysis to soil type prediction in a desert landscape. Ecological Modelling, v. 181, n. 1, p. $1-15,2005$.

SIQUEIRA, M.F.; DURIGAN, G.; JÚNIOR, P.M.; PETERSON, A.T. Something from nothing: Using landscape similarity and ecological niche modeling to find rare plant species. Journal for Nature Conservation, p. 8, 2008.

SILVA, V. de N.E et al. Formulating conservation targets for a gap analysis of endemic lizards in a biodiversity hotspot. Biological Conservation, v. 180, p. 1-10, 2014.

SKOLE, D.; TUCKER, C. Tropical Deforestation and Habitat Fragmentation in the Amazon: Satellite Data from 1978 to 1988. Science, v. 260, n. 5116, p. 1905-1910, 1993.

SOBERÓN, J.; PETERSON, A.T. Interpretation of models of fundamental ecological niches and species distributional areas. Biodiversity Informatics, v. 2, p. 1-10, 2005.

SOITO, J.L.S.; FREITAS, M.A.V. Amazon and the expansion of hydropower in Brazil: Vulnerability, impacts andpossibilities for adaptation to global climate change. Renewable and Sustainable Energy Reviews. v. 15, p.3165-3177, 2011.

SOMBROEK, W. Spatial and Temporal Patterns of Amazon Rainfall. Journal of the Human Environment, v. 30, n. 7, p. 388-396, 2001.

SØRENSEN, R.; ZINKO, U.; SEIBERT, J. On the calculation of the topographic wetness index: evaluation of different methods based on field observations. Hydrology and Earth System Sciences, v. 10, n. 1, p. 101-112, 2006.

STOCKWELL, D.R.B.; NOBLE, I.R. Induction of sets of rules from animal distribution data: A robust and informative method of data analysis. Mathematics and Computers in Simulation, v. 33, n. 5-6, p. 385-390, 1992.

STOCKWELL, D. The GARP modeling system: problems and solutions to automated spatial prediction. International Journal of Geographical Information Science, v. 13, n.2, p.143-158,1999.

TERBORGH, J.W.; ANDRESEN, E. The composition of Amazonian forests: patterns at local and regional scales. Journal of Tropical Ecology, v. 14, p. 645 664, 1998.

TER STEEGE, H. et al. Continental-scale patterns of canopy tree composition and function across Amazonia. Nature, v. 443, n. 7110, p. 444-447, 2006.

TER STEEGE, H. et al. Hyperdominance in the Amazonian tree flora. Science (New York, N.Y.), v. 342, n. 6156, p. 1243092, 2013.

TER STEEGE, $\mathrm{H}$. et al. Estimating the global conservation status of more than 15,000 Amazonian tree species. Sci. Adv, p. 9-11, 2015.

TOPODATA. Banco de Dados Geomorfométricos do Brasil. Disponível em: <http://www.webmapit.com.br/inpe/topodata> Acesso em: 30 de nov. 2015.

USGS. United States Geological Survey. Disponível em: <http://www.http://earthexplorer.usgs.gov> Acesso em: 30 de nov. 2015. 
VALERIANO, M. M.; ROSSETTI, D. F. Topodata: Brazilian full coverage refinement of SRTM data. Applied Geography (Sevenoaks), v. 32, p. 300-309, 2011.

ZUQUIM, G. et al. Broad Scale Distribution of Ferns and Lycophytes along Environmental Gradients in Central and Northern Amazonia, Brazil. Biotropica, v. 44, p. 752-762, 2012.

WAMELINK, G.W.; GOEDHART, P.W.; FRISSEL, J.Y. Why some plant species are rare. PLoS ONE, v. 9, n. 7, p. 1-7, 2014.

WATSON, D. M. et al. A conceptual framework for studying species composition in fragments , islands and other patchy ecosystems. Journal of Biogeography, v. 29, p. 823$834,2002$.

WILLIAMS, P. Some properties of rarity scores used in site quality assessment. British Journal of Entomolgy and Natural History, 2000.

WITTMANN, F. et al. Tree species composition and diversitygradients in white-water forests across the Amazon Basin. Journal of Biogeography, 2006.

WITTMANN, F.; HOUSEHOLDER, E.; PIEDADE, M. T. F.; de ASSIS, R. L.; SCHÖNGART, J.; PAROLIN, P.; JUNK, W. J. Habitat specifity, endemism and the neotropical distribution of Amazonian white-water floodplain trees. Ecography, v. 35, p. $1-18,2012$.

YU, J.; DOBSON, F.S. Seven forms of rarity in mammals. Journal of Biogeography, v. 27, p. 131-139, 2000. 
